

Polth, Michael (2011): Zur Artikulation von Tonfeldern bei Brahms, Debussy und Stockhausen. ZGMTH 8/2, 225-265. https://doi.org/10.31751/645

\section{(C) 2011 Michael Polth}



Dieser Text erscheint im Open Access und ist lizenziert unter einer Creative Commons Namensnennung 4.0 International Lizenz.

This is an open access article licensed under a

Creative Commons Attribution 4.0 International License.

veröffentlicht / first published: 17/11/2011

zuletzt geändert / last updated: 25/10/2013 


\title{
Zur Artikulation von Tonfeldern bei Brahms, Debussy und Stockhausen
}

\author{
Michael Polth
}

\begin{abstract}
Tonfelder sind Typen des musikalischen Zusammenhangs, die durch einzelne Kompositionen instantiiert werden. Sie analytisch zu zeigen, heißt immer auch, den jeweils singulären Bedingungen nachzuspüren, unter denen sie stehen. Tonfelder zeigen sich bei Brahms indirekt: Rhythmische Verschiebungen von Tönen, die zu traditionellen Strukturen gehören, lassen ssekundär neue Tonverbindungen hören. Dem gegenüber lassen sich die Tonfelder bei Debussy als sprimäre Erscheinungen verstehen. Zwischen den Quintenreihen, die das Satzganze artikulieren, und den übrigen Tonfeldern, die den Kontrast schaffen, bestehen vielfältige Beziehungen, die vor allem dann deutlich werden, wenn man die Tonfelder als Skalen notiert. Schließlich wird gezeigt, dass die Analyse nach Tonfeldern auch bei Stockhausen zu einem schlüssigen Ergebnis führt, wenn man anerkennt, dass die sogenannte sserielle Technikı als Voraussetzung zur Artikulation von Tonfeldern dienen kann.
\end{abstract}

Dieser Beitrag stellt drei analytische Studien zu je einem Klavierstück von Johannes Brahms, Claude Debussy und Karlheinz Stockhausen vor. Die Studien sind unabhängig voneinander entstanden und werden hier mehr gereiht als miteinander verbunden. Sie wurden von der Frage geleitet, welche satztechnischen Bedingungen erfüllt sein müssen, damit die Behauptung plausibel erscheint, dass sich die Töne der jeweiligen Kompositionen zu Tonfeldern zusammenschließen. Die Frage trifft ein Kernproblem der TonfeldTheorie: Als Analysierender darf man von der Hypothese ausgehen, dass ein simplizites Wissen $\imath^{1}$ um Tonfelder die kompositorischen Entscheidungen der Komponisten unbewusst gelenkt hat. Ein Tonfeld wiederum kann man sich als einen Typ des musikalischen Zusammenhangs vorstellen, der durch einzelne Kompositionen instantiiert wird. Als instantiiertes aber steht das Tonfeld ganz unter den Bedingungen der jeweiligen Komposition. Nun sind die hier untersuchten Kompositionen, das Intermezzo op. 76,7 von Brahms, The little Shepherd von Debussy und Klavierstück III von Stockhausen, hinsichtlich der Grundlagen des musikalischen Zusammenhangs denkbar verschieden, und doch sollen in ihnen angeblich >dieselben Tonfelder zu finden sein. Wenn diese Behauptung plausibel sein soll, darf sie nicht nur auf allgemeine und abstrakte Erwägungen gegründet sein. Vielmehr müssen die hier vorgestellten Analysen einen Weg aufzeigen, wie sich die jeweils singulären (historischen) Verhältnisse eines Tonsatzes als Voraussetzung für die Konstitution von Tonfeldern verstehen lassen.

1 Statt vom simpliziten Wissen könnte man - ungeachtet der Bedeutungsunterschiede im Detail auch von smusikalischem Denken` (Eggebrecht) oder von simpliziter Theorie`(Dahlhaus) sprechen. 


\section{Einführung}

In dieser Einführung werden zunächst die Typen von Tonfeldern, von denen die Vertreter der Tonfeldanalyse derzeit ausgehen, sowie einige wichtige Möglichkeiten ihrer Artikulation erläutert. Es folgen einige grundsätzliche Überlegungen zur Tonfeld-Analyse und schließlich zu den verschiedenen Eigenarten einer Tonalität, die auf Tonfeldern beruht. ${ }^{2}$

\section{Typen von Tonfeldern}

Albert Simon kennt drei Typen von Tonfeldern: Funktionen, Konstrukte und Quintenreihen (Beispiel 1). Tonfelder sind strukturierte Tonvorräte. Eine Funktion besteht aus acht Tönen: vier Grundtönen im Abstand von jeweils einer kleinen Terz und vier Quinttönen. Konstrukte bestehen aus sechs Tönen: drei Grundtönen im Abstand von jeweils einer großen Terz und drei Quinttönen. Infolge dessen gibt es drei Funktionen und vier Konstrukte.

Quintenreihen sind zusammenhängende Ausschnitte aus einer nach beiden Seiten offenen Kette von reinen Quinten. Eine Quintenreihe besteht aus mindestens drei und höchstens neun Tönen (die Namen richten sich nach der Zahl der enthaltenen Töne). Von daher gibt es Quintenreihen in sieben Größen (von denen jede auf jedem denkbaren Ton beginnen kann).

Funktionen

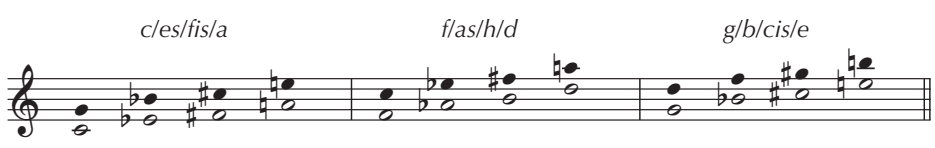

Konstrukte

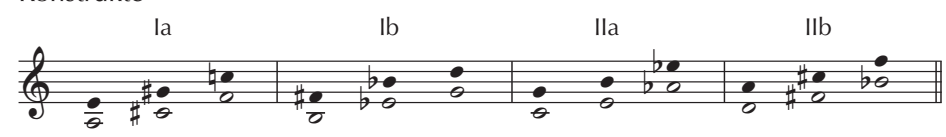

Quintenreihen $f$ bis ...
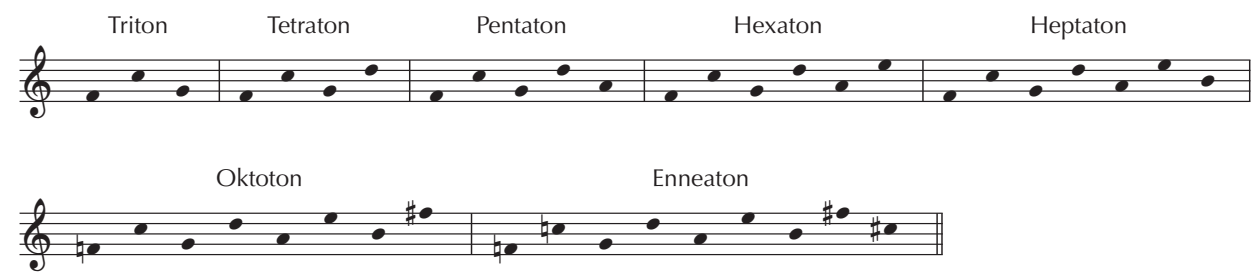

Beispiel 1: Die drei Funktionen, die vier Konstrukte und sieben verschiedene Quintenreihen (hier beginnend auf $f$ )

2 Beinahe alle Aspekte, die in der folgenden Einführung erwähnt werden, finden sich implizit oder explizit bei Haas 2004. 
Funktionen und Konstrukte besitzen aufgrund ihres Aufbaus eine feste Zahl von Tönen und können daher vollständig sein, Quintenreihen hingegen sind auf keine bestimmte Größe festgelegt (beispielsweise ist ein Heptaton nicht vollständiger als ein Hexaton). Funktionen und Konstrukte besitzen Grundtöne, nämlich die jeweils vier bzw. drei tieferen Töne der beteiligten Quinten. Quintenreihen hingegen haben für sich genommen, wenn nicht besondere Umstände vorliegen, keinen Grundton.

Das sharmonische Hexaton`, das zum sharmonischen Hepta-^ oder `Oktoton` erweitert werden kann, stellt zwar keinen eigenständigen vierten Tonfeld-Typ dar, hat sich jedoch bislang in einigen Analysen als funktional bedeutsam erwiesen. Im Unterschied zum ınormalen` Hexaton erscheinen die Ecktöne (in Beispiel 2 fis und es) in alterierter Fassung (aus den reinen werden an den entsprechenden Stellen verminderte Quinten). Während das snormale Sekundabstand zusammengesetzt werden kann, besteht das harmonische Hexaton aus einem unteren Moll- und einem oberen Dur-Akkord. Durch Hinzufügen eines weiteren Tons (in Beispiel $2 h$ oder $b$ ) kann es zu einem harmonischen Heptaton, durch Hinzufügen beider Töne ( $h$ und $b$ ) zum harmonischen Oktoton erweitert werden.

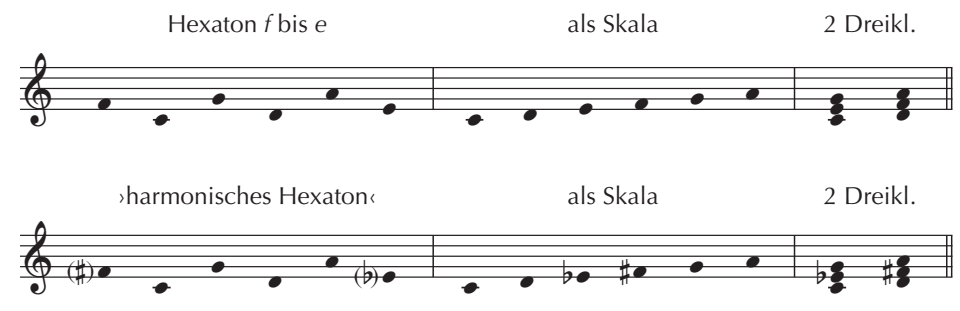

sharmonisches Heptaton zu G-Dur

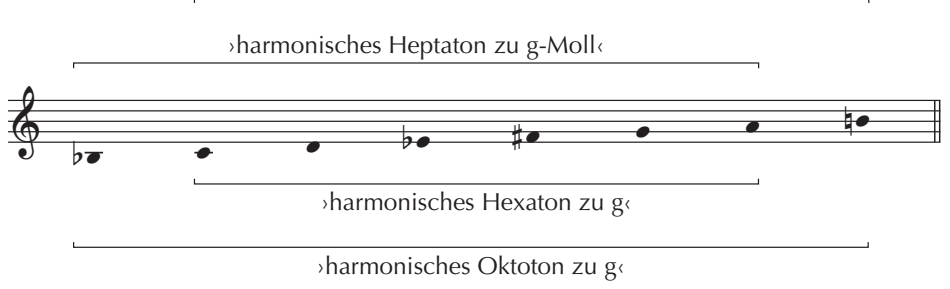

Beispiel 2: ^Harmonische` Quintenreihen (Hexaton, Heptaton, Oktoton)

Hilfreich für die Analyse ist die Kenntnis charakteristischer Schnittmengen zwischen Tonfeldern (Beispiel 3). So stellt ein >Dreiklang`mit Dur- und Moll-Terz die gemeinsamen Töne einer Funktion und eines Konstrukts dar. Die Schnittmenge zwischen einem Hexaton und einem Konstrukt bildet eine Konstellation aus zwei Quinten im Großterzabstand (Haas nennt sie $\curvearrowright$ Viereckı) und zwischen Funktion und Oktoton eine Konstellation aus einem Dur- und einem Moll-Akkord im Abstand einer übermäßigen Quarte bzw. verminderten Quinte (nach Haas ein `Sechseckı). 
Tonfeld 1

Funktion c/es/fis/a

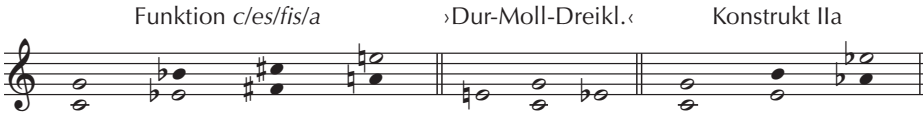

Hexaton $f$ bis e

,Viereck

Konstrukt la

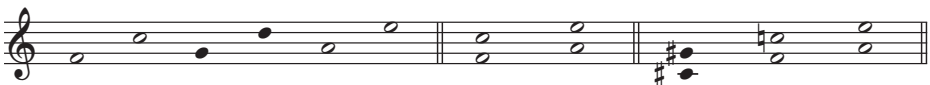

Oktoton $f$ bis fis $\quad$ sechseck $\quad$ Funktion f/as/h/d

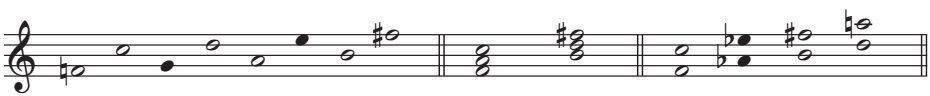

Beispiel 3: Beispiele für Schnittmengen zwischen Tonfeldern (`Dur-Moll-Dreiklangı, ,Viereckı, 'Sechseckı)

Schließlich gibt es zwischen Tonfeldern, die einander ähneln, charakteristische Wege des Übergangs. Beispielsweise kann ein Hexaton in ein Konstrukt überführt werden, indem die mittlere beteiligte Quinte durch Gegenbewegung in Halbtonschritten in eine Quarte verwandelt wird (Beispiel 4a). Oder: Ein Konstrukt besteht aus zwei Dreitongruppen mit der Intervallfolge kleine Sekunde - kleine Terz (die Intervallfolgen der beiden Dreitongruppen erscheinen zueinander spiegelverkehrt). Wird eine der beiden Dreitongruppen um einen Halbtonschritt auf die andere zubewegt, entsteht eine sechstönige (und damit unvollständige) Funktion (Beispiel 4b).

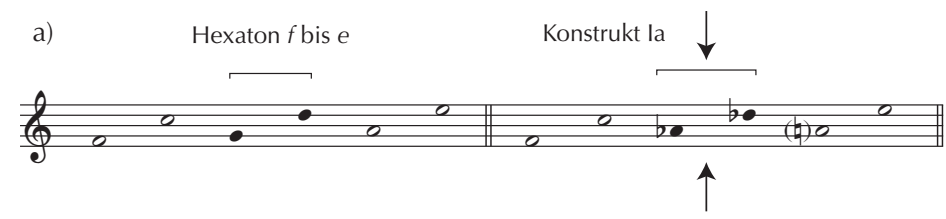

b)

Konstrukt Ila

Funktion f/as/h/d (unvollst.)

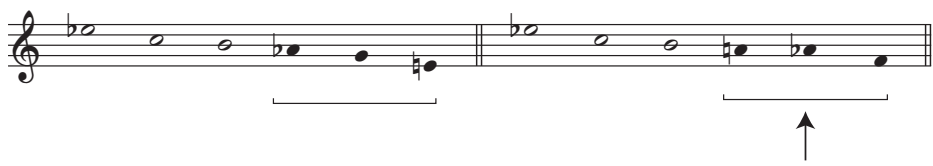

Beispiel 4: Beispiele für Übergänge

a) Hexaton $\rightarrow$ Konstrukt, b) Konstrukt $\rightarrow$ Funktion

\section{Artikulation von Tonfeldern}

Tonfelder besitzen bestimmte Klangeigenschaften. Diese resultieren unter anderem aus der Beschaffenheit des Tonfeldes selbst und aus der Art und Weise, wie das Tonfeld artikuliert, d. h. gegliedert wird. Die Zahl der Möglichkeiten, die Töne eines Tonfeldes im 
Tonsatz zu verteilen, dürfte theoretisch gegen Unendlich tendieren. Dennoch lassen sich einige Typen der Artikulation benennen, denen gegenüber die tatsächlichen Artikulationen innerhalb der Kompositionen als konkrete Ausformulierungen verstanden werden dürfen. Die hier vorgestellten Artikulationstypen können auf allen Schichten einer Komposition erscheinen (zur Schichtenanalyse s.u.).

a)

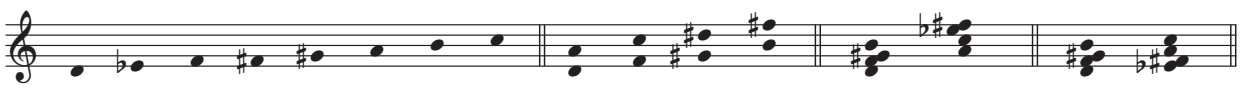

e)

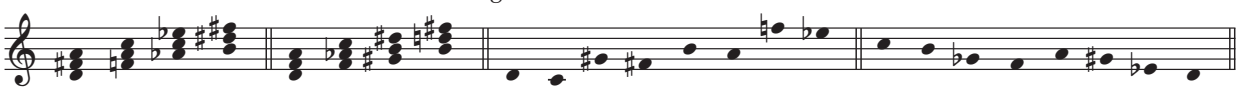

i)

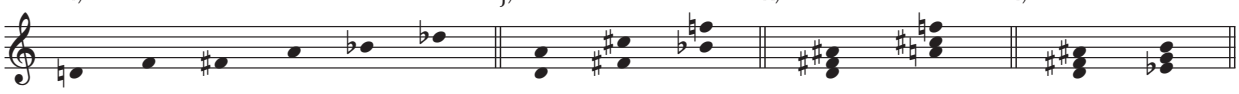

$\mathrm{m})$

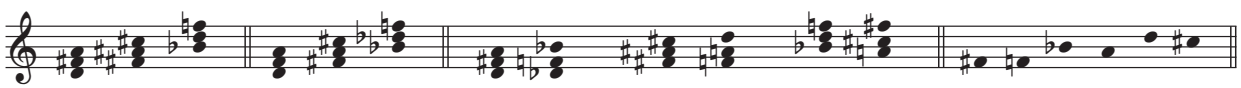

q)

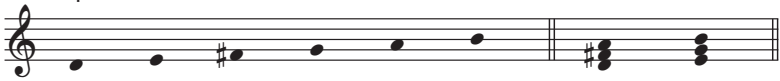

Beispiel 5: Artikulationsmöglichkeiten der Tonfelder (Auswahl)

In der Literatur findet man eine Funktion häufig als Halbtonganztonskala, als Folge von vier Quinten, zwei ganzverminderten Septakkorden im Quintabstand, zwei ganzverminderten Septakkorden im Halbtonabstand oder vier Dur- oder Moll-Akkorden im Kleinterzabstand oder als Konstellation aus vier Ganztonschritten bzw. vier Halbtonschritten.

In gleicher Weise kann ein Konstrukt als Skala (abwechselnd aus kleiner Terz und Halbtonschritt), als Folge von drei Quinten im Großterzabstand, von zwei übermäßigen Dreiklängen im Quintabstand bzw. im Abstand eines Halbtonschritts, von drei Dur- oder Moll-Akkorden im Großterzabstand, als Kombination aus einem Dur- und einem MollAkkord oder als drei Halbtonschritte erscheinen.

Jedes Tonfeld einer Quintenreihe hat - durch die je eigenen Intervallkonstellationen spezifische Eigenschaften. Auch die Töne von Quintenreihen finden sich in unterschiedlichen Anordnungen. Beispielsweise kann ein Hexaton als sechstöniger Skalenausschnitt erscheinen oder als Kombination aus einem Dur- und einem Mollakkord im Sekundabstand.

Verschiedene Artikulationsformen können dasselbe Tonfeld sehr unterschiedlich erscheinen lassen. Hinzu kommt, dass die Tonfeld-Theorie den Betrachter dazu anhält, Tonfelder als funktionale Einheiten zu verstehen. Im Gegensatz zu Konstellationen, die 
a) T. 1-6
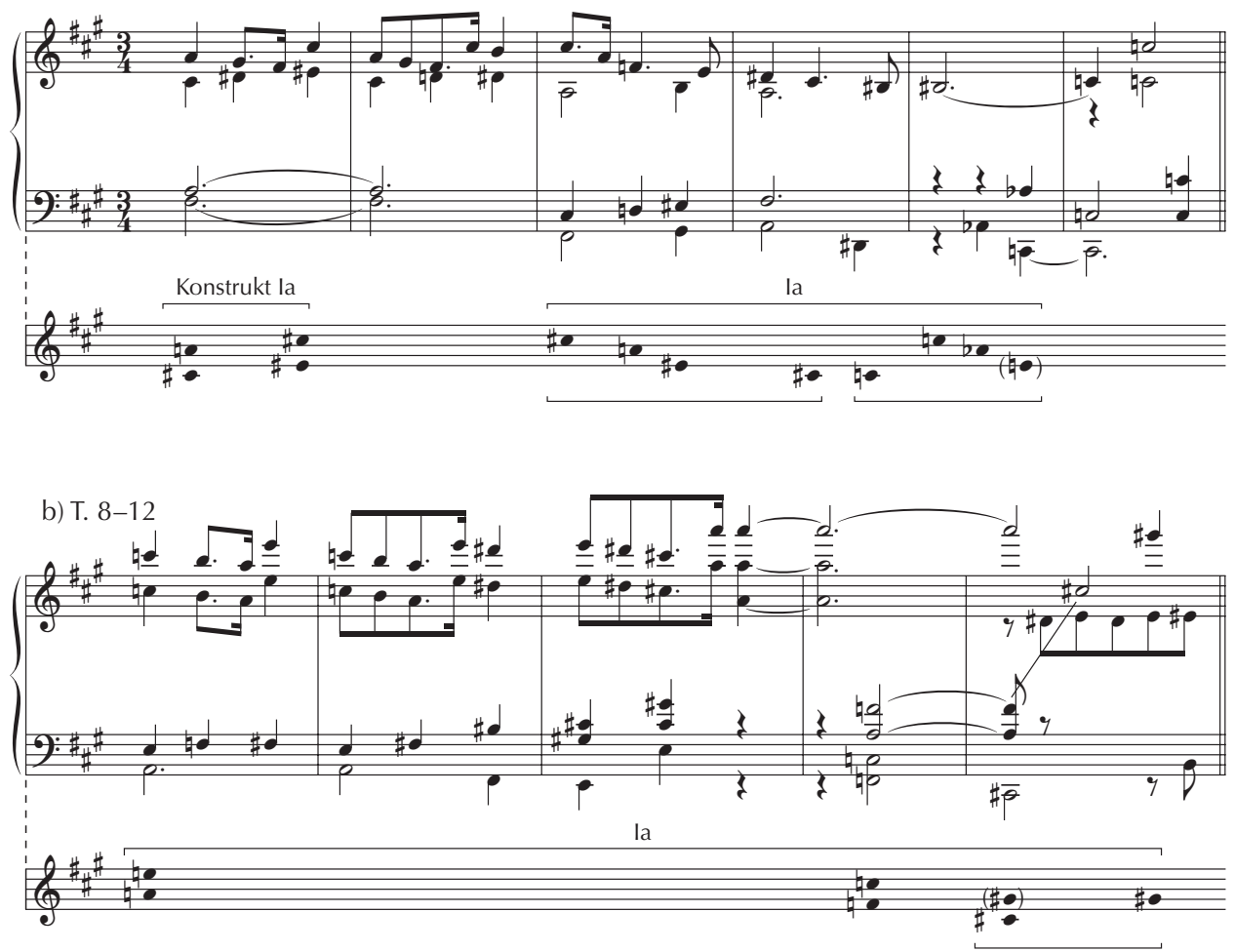

Beispiel 6: Arnold Schönberg, Streichquartett op. 10, 1. Satz, a) T. 1-6, b) T. 8-12

den Charakter von sDaten kordfolgen betrachtet), kann eine funktionale Einheit auch dann gegeben sein, wenn die Elemente unvollständig, voneinander getrennt oder mit Elementen anderer funktionaler Einheiten vermischt erscheinen. Gemeinsam wäre allen konkreten Artikulationen eines Tonfeldes ein bestimmter Typ von Klangeigenschaft.

Im ersten Satz von Schönbergs Streichquartett op. 10 werden die Konstrukte la, Ib und IIb nicht nur unterschiedlich artikuliert, es werden auch die Teilmengen der Konstrukte an ihren Erscheinungsorten auf verschiedene Weise in den Tonsatz integriert. Da das Netz der Beziehungen in diesem Satz sehr dicht ist und die Konstrukte überdies nicht in der strukturellen Hintergrundschicht des Satzes angesiedelt sind, erscheinen sie an allen Stellen des Satzes mit Tönen anderer Tonfelder vermischt. Dennoch tritt der dem Konstrukt eigene Typ von Klangeigenschaft ${ }^{3}$ als das bestimmende Moment des lokalen Klangs an jeder Stelle hervor.

Zu Beispiel 6a: Lediglich angedeutet wird das Konstrukt la im ersten Takt durch die Töne a, cis und eis, die in den oberen Streichern als Sexten (auf der Eins und der Drei)

3 Vgl. hierzu die Beiträge von Sotirianos und Schiltknecht in dieser Ausgabe. 
c) T. $17-24$

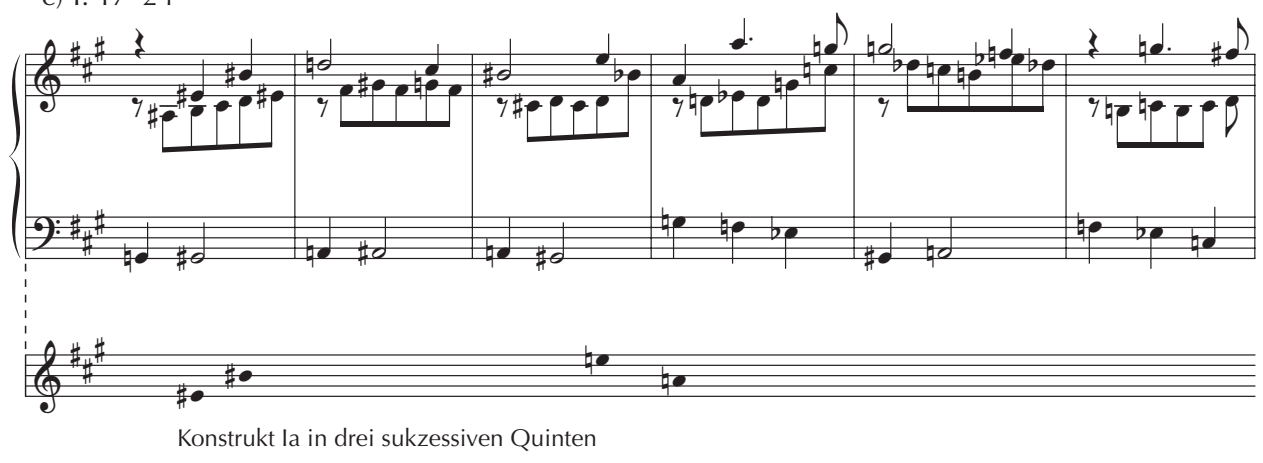

d) T. $38-40$

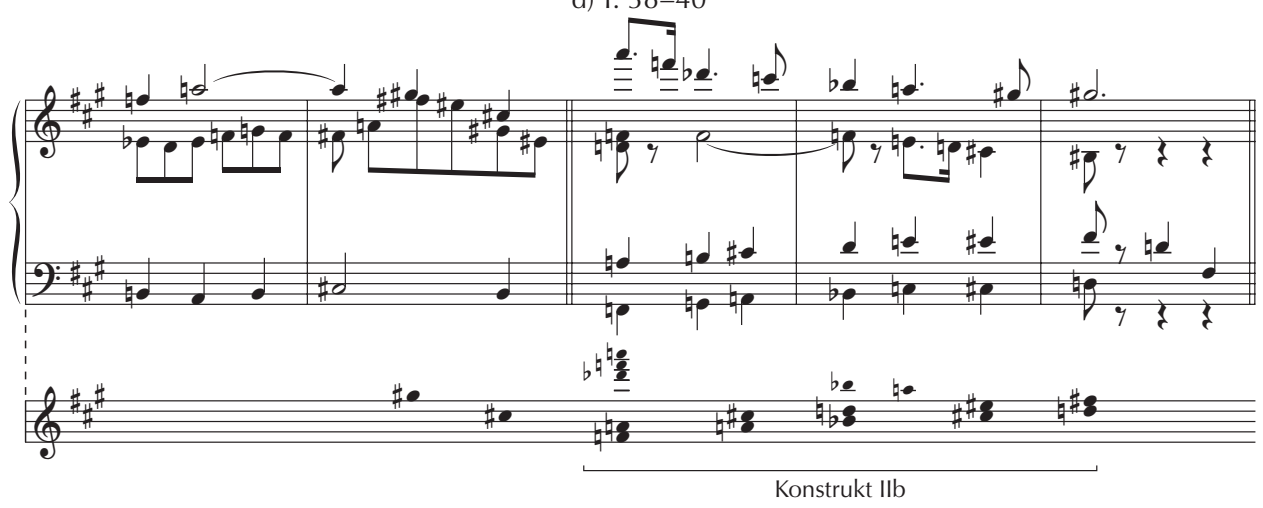

Beispiel 6 (Fortsetzung): c) T. 17-24, d) T. 38-40

erscheinen. Diese Töne, die eine mögliche Hälfte des Konstrukts darstellen, kehren in Takt 3 melodisch als übermäßiger Dreiklang cis-a-eis wieder und werden in Takt 5 durch den komplementären (um einen Halbtonschritt tiefer liegenden) übermäßigen Dreiklang c-as-e zu einem beinahe vollständigen Konstrukt ergänzt (es fehlt nur der Ton e). Der Übergang in den tieferen Dreiklang wird durch den rhythmisch exponierten Halbtonschritt cis-his sinnfällig; mit Erreichen dieses Dreiklangs wechselt die musikalische Textur.

Zu Beispiel 6b: In den Takten 8 bis 12 wird dasselbe Konstrukt als Folge von drei Quinten vollständig dargestellt. Die Quinten a-e und $f$-c, über denen die Akkorde a-Moll und F-Dur stehen, erscheinen zu Beginn der Takte 8 und 11 als tiefste Töne. Im Falle der Quinte cis-gis erklingt nur cis als tiefster Ton des Cis-Dur-Akkordes in Takt 12. gis hingegen erscheint verzögert auf der dritten Zählzeit als beinahe höchster und zugleich abschließender Ton des ersten Formabschnitts (Takt 12 ist zugleich Beginn des zweiten Teils). ${ }^{4}$

4 Der cis-Moll-Akkord in Takt 10, der nur kurz und als Sextakkord erscheint, gehört nicht auf derselben Schicht zum Konstrukt wie die übrigen genannten Quinten. Er dient der lokalen Vermittlung zwischen den Akkorden a-Moll und F-Dur, indem er das fünf Takte umfassende Konstrukt auf engstem Raum wiederholt. 
e) T. $66-70$

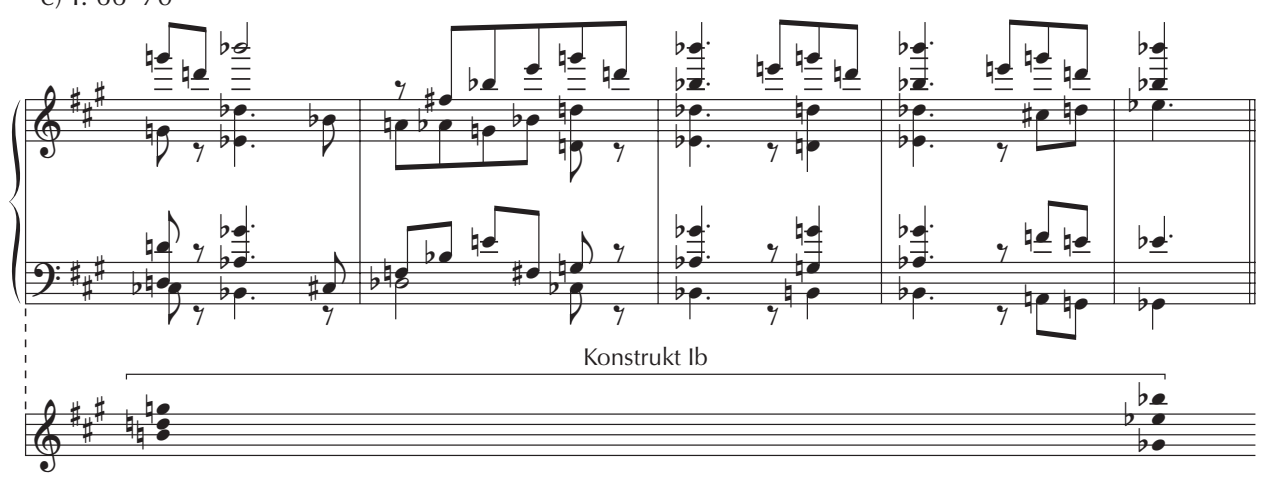

Beispiel 6 (Fortsetzung): e) T. 66-70 (jeweils Notentext und Analyse)

Zu Beispiel 6c: Im zweiten Formabschnitt erscheinen die drei Quinten von Konstrukt la als sukzessive Intervalle. Als solche sind sie prominente Bestandteile des Themas in der Bratsche: Die Quinte $f_{-} c$ (hier notiert als eis-his) eröffnet die zweite Hälfte des Themas (T. 17), die Quinte cis-gis beschließt sie (T. 24).

Zu Beispiel 6d: Das Konstrukt Ilb (T. 38-40) beendet eine kurze Wiederaufnahme des ersten Themas (T. 34-40). In der Hauptsache steckt das Tonfeld in der Folge der großen Terzen zwischen Bratsche und Violoncello (jeweils auf erster und dritter Zählzeit - man beachte die melodischen Halbtonschritte an den Taktübergängen). Aber auch Teile der Oberstimme sind an der Darstellung des Tonfelds beteiligt.

$\mathrm{Zu}$ Beispiel 6e: Die rhythmisch auffällige Akkordfolge, die in den Takten 66 bis 70 so etwas wie den strukturellen Schluss der Exposition bildet, enthält das Konstrukt Ib (das Komplementär-Tonfeld zum Konstrukt des Anfangs, das sich mit jenem zum Total der zwölf Töne ergänzt) in Gestalt der Dreiklänge G-Dur und es-Moll. Der G-DurSextakkord eröffnet die Akkordfolge in Takt 66, der es-Moll-Sextakkord beschließt sie in Takt 70 (nur der letzte der vier Akkorde mit Spitzenton $b^{3}$ ist ein einfacher Dreiklang, die vorangehenden sind Pentatone von ges bis $b$ ).

\section{Zur Tonfeld-Analyse}

Tonfeldanalyse geht - wie bereits erwähnt - von der Hypothese aus, ein simplizites Wissen um Tonfelder (als Typen musikalischen Zusammenhangs) habe die Komponisten bei der Erfindung musikalischer Abläufe geleitet. ${ }^{5}$ Wenn im Folgenden dennoch von Tonfeldern wie von Tatsachen gesprochen wird (also beispielsweise gesagt wird, ein Komponist habe in seinem Stück bestimmte Tonfelder deutlich gemacht oder die Komposition selbst stelle bestimmte Tonfelder dar), dann geschieht dies allein um der sprachlichen Einfachheit willen.

5 Die Hypothese stellt keine Behauptung über ein reales, sondern über ein idealtypisch rekonstruiertes Denken dar. 
Ungebundenheit

Die Darstellung von Tonfeldern ist nicht an einen Stil, an eine Kompositionstechnik oder an eine bestimmte Gestaltungsweise des Tonsatzes gebunden. Grundsätzlich können die Töne eines Tonfeldes in beliebiger Anordnung erscheinen: miteinander verbunden oder zeitlich getrennt, linear oder akkordisch usw. Der Ausdruck ı-feld impliziert gerade diese prinzipielle Ungebundenheit der Verteilung. Verlangt wird lediglich, dass die Töne als zu einem Tonfeld gehörig rezipiert werden können.

Die Tonfeld-Theorie setzt implizit voraus, dass dieselben Strukturen sowohl die shorizontale als auch die svertikale` Dimension des Tonsatzes bestimmen können. Diese Voraussetzung wird der kompositorischen Situation im späten 19. und frühen 20. Jahrhundert durchaus gerecht; denn es dürfte nicht übertrieben sein zu sagen, dass Tonfelder bei Liszt, Bruckner, Strauss und Schönberg gleichermaßen von Melodien und Akkorden dargestellt werden. Selten ist die Situation allerdings so deutlich wie in den Takten 161166 des ersten Satzes aus Bruckners 9. Symphonie, die im Wesentlichen ein Triton a-e- $h$ artikulieren (mit Ausnahme der Umspielungen des Tones e in den Takten 164-166). Die Struktur der Quintenreihe bestimmt gleichermaßen die Bildung von horizontalen und vertikalen Ereignissen.
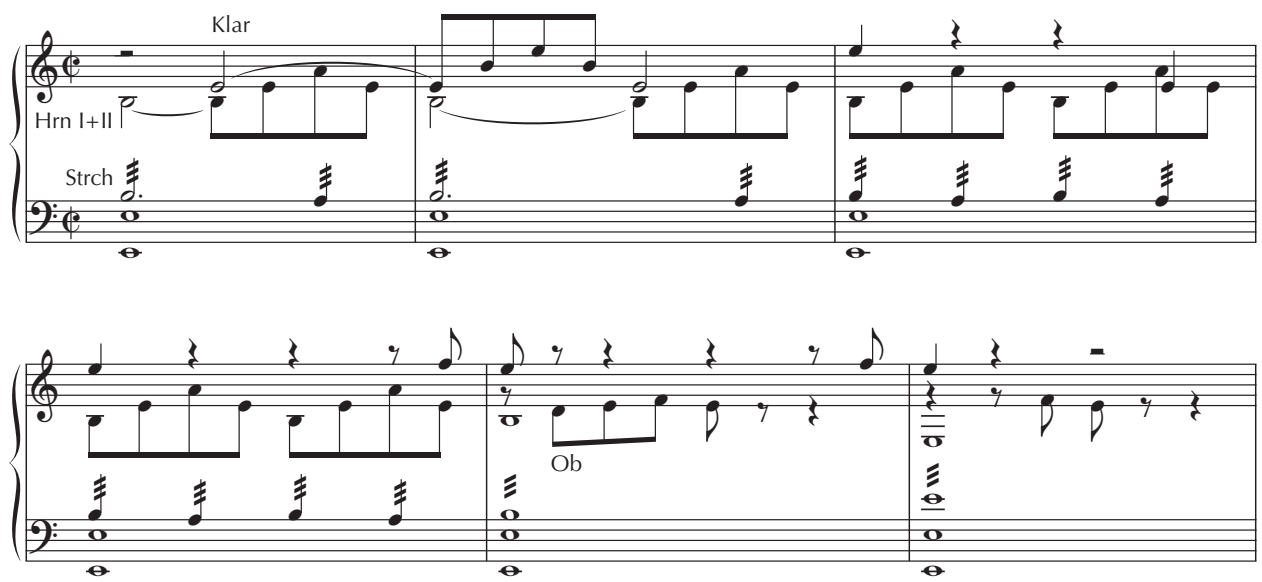

Beispiel 7: Anton Bruckner, Symphonie Nr. 9, 1. Satz, T. 161-166 (Particell)

Schichtenanalyse

Die Auffassung, dass Tonfelder nicht (oder nicht ausschließlich) Materialvorräte darstellen, aus denen sich ein Komponist bedient, sondern Begriffe für funktionale Einheiten, die sich in den Beziehungen der beteiligten Töne manifestieren, hat zur Konsequenz, dass eine Tonfeld-Analyse methodisch als Schichtenanalyse betrieben werden muss. Erstens zielt die Schichtenanalyse nicht allein auf das Vorkommen bestimmter Töne, sondern auf die (vom Analysierenden unterstellte) Zusammengehörigkeit der Töne zu 
einer Einheit. Sie konstatiert nicht das Vorkommen von Ereignissen, sondern interpretiert deren Erscheinen. Zweitens wird die Schichtenanalyse der Beobachtung gerecht, dass Tonfelder musikalische Zusammenhänge auf unterschiedlichen Ebenen der Formbildung begründen können. Wer ein hintergründiges Tonfeld im Diagramm notiert, will damit sagen, dass die genannten Töne das Ganze einer Komposition artikulieren. Eine Position im Mittelgrund weist auf Beziehungen etwa in der Größenordnung einzelner Formabschnitte, und vordergründige Tonfelder geben lokale Zusammenhänge wieder. ${ }^{6}$

Die Schichtenanalyse ist somit die methodische Voraussetzung dafür, die strukturelle Komplexität einer (Tonfeld-)Komposition hinreichend darstellen zu können. Umgekehrt ermöglicht sie dem Leser, die Ereignisse der unterschiedlichen Schichten konkret im Tonsatz zu identifizieren, beispielsweise einen Ton des Hintergrundes in der Partitur zu finden und überdies zu erkennen, wie dieser Ton in den Vordergrund eingebettet ist. Dieser >didaktische، Aspekt der Schichtenanalyse ist wesentlich, wenn die Analyse den Anspruch erheben möchte, zum Hören von Tonfeldern (auf unterschiedlichen Ebenen der Komposition) anzuleiten. Im konkreten Fall könnte beispielsweise die Schwierigkeit bestehen, dass die Töne eines hintergründigen Tonfeldes über die gesamte Komposition verteilt sind und dass man das Erscheinen eines (isolierten) hintergründigen Tons zunächst nicht als das Wirken eben eines Hintergrundtones wahrnehmen kann. Wie sollte man einen einzelnen Ton mit Tönen in weiter Entfernung zusammen hören können, wenn an dieser Stelle keine Hinweise auf die `Hintergründigkeitı des Tons vorliegen? Die Schichtenanalyse benennt solche Hinweise. Möglich ist, dass an einer Stelle, an der ein Hintergrund-Ton erklingt, weitere Töne des Hintergrundes erscheinen (Töne also, deren sstruktureller Erscheinungsort woanders liegt), so dass die umspannende Struktur des Hintergrundes als Vordergrundphänomen wiederholt wird (die Analyse der Klavierstücke von Brahms und Debussy wird weitere Möglichkeiten aufzeigen). ${ }^{7}$

6 Wie viele Schichten man für eine Komposition annimmt, hängt derzeit noch sehr stark von den eigenen Darstellungsabsichten ab. Nicht ausgeschlossen ist allerdings, dass sich mit zunehmender Analyse-Erfahrung die Annahme eines bestimmten Modells oder mehrerer unterschiedlicher Modelle mit festgelegter Schichtenanzahl als methodisch sinnvoll erweist.

7 Schließlich hilft die Schichtenanalyse bei einem Problem, bei dem alle Analysemethoden versagen, deren Betrachtung sich auf den Vordergrund beschränkt. Kaum eine Komposition enthält ihre Tonfelder stets vollständig, unvermischt und sauber gereiht. In fast jeder Komposition haben wir es an den allermeisten Stellen mit Tonkonstellationen zu tun, die nur partiell in ein bestimmtes Tonfeld passen (überdies füllen die Töne, die in ein bestimmtes Tonfeld passen, dieses oft nicht vollständig aus). Man sollte in dieser salltäglichen Situation kein methodisches Problem sehen (etwa von der Art: Wenn Tonfelder sich nicht klar und einfach zeigen lassen, dann ist der Ansatz, der auf ihnen basiert, unangemessen), sondern einen Normalzustand angesichts der Komplexität der betrachteten Phänomene. Daher gilt es, den Ansatz nicht durch fragwürdige Vereinfachungen für die Anwendung gefügig zu machen. Zu solchen Vereinfachungen würde gehören, Töne, die nicht in das gewünschte Tonfeld passen, als `Ausnahmen zu deklarieren oder sunpassende` Töne - im Sinne traditioneller kontrapunktischer Kategorien - als Nebennoten, Umspielungen, Durchgänge etc. zu interpretieren, statt ihren Sinn für die Artikulation von Tonfeldern anzugeben. Die Schichtenanalyse bietet nicht nur die Möglichkeit, Töne, die zeitgleich oder in unmittelbarer Nachbarschaft zueinander erklingen, verschiedenen Schichten zuzuordnen. Sie zwingt vielmehr dazu, auch die sunpassenden Töne einem konkreten, durch Tonfelder artikulierten Zusammenhang zuzuordnen, dessen Plausibilität sich aus der Gesamtanalyse heraus erweisen muss. 


\section{Tonfelder und sneue Tonalitäts}

Unter der Voraussetzung, dass die Tonfelder die bestimmenden Funktionen des musikalischen Zusammenhangs in der Musik des späten 19. und frühen 20. Jahrhunderts gewesen sind, kann der gesamte Tonfeld-Komplex als Paradigma einer sneuen Tonalitäts gelten. ${ }^{8}$ Diese neue Tonalität bringt Phänomene hervor, die es im 18. und frühen 19. Jahrhundert in dieser Form noch nicht gegeben hat und von denen zwei erwähnt werden sollen.

\section{Kontext}

Tonfelder begründen einen musikalischen Kontext, der uns den einzelnen Ton auf andere Weise hören lässt als unter den Bedingungen der traditionellen Tonalität. Vereinfacht gesagt, lassen die Tonsätze des 18. und frühen 19. Jahrhunderts einen Ton vorzugsweise in seinen Beziehungen zur Tonart erscheinen (als Tonstufe oder Teil einer Akkordstufe), während uns die Beziehungen in einer Tonfeld-Komposition den einzelnen Ton eher als materialen, stofflichen Gegenstand hören lassen, sozusagen so, 'wie er selbst klingt، (letzteres ist selbstverständlich ein durch Kontext hervorgerufener ästhetischer Schein). Tonfeld-Kontexte, die einen derartigen Eindruck zu erzeugen vermögen, können sehr verschieden sein. Im Extremfall ist ein Ton Teil einer in sich bewegten Klangfläche, die keine lokale Tonart und keine distinkten Akkorde deutlich macht. In diesem Fall trägt der Einzelton (für den Hörer) nicht als Stufe oder Akkordbestandteil zum Gesamtklang der Klangfläche bei, sondern dadurch, dass seine schiere Anwesenheit eine Klangkomponente beisteuert (und eben diese Funktion, Klangkomponente zu sein, lässt uns den Ton selbst eher als ıstofflichen` Bestandteil dieser Fläche wahrnehmen). Klangflächen bilden nicht die einzige Darstellungsform, in der ein Ton auf diese oder ähnliche Art wahrgenommen werden kann. Auch Zusammenklänge, die nicht auf Dreiklänge oder Septakkorde reduziert werden können, Akkordfolgen, die nicht an traditionelle Tonalität gebunden sind, unter Umständen sogar rasche oder mit Stimmbewegungen angereicherte Akkordwechsel: alle diese von Bruckner, Strauss und Schönberg her bekannten Verfahren lenken die Aufmerksamkeit tendenziell dahin, wie der Ton als Komponente einer (strukturierten) Menge von Tönen wirkt. (Auch die erhöhte Aufmerksamkeit im späten 19. Jahrhundert für die sogenannte Klangfarbe ließe sich von hier aus als eine partielle Ausprägung der erhöhten Aufmerksamkeit für das ıStofflicheı am Ton beschreiben.)

Auch Tonfeld-Kompositionen können lokale Tonarten ausprägen. Doch deren Funktion hat sich gegenüber der Funktion von Tonarten im 18. und frühen 19. Jahrhundert verändert. Bei Bach, Mozart und Chopin etwa gehörte die lokale Tonart zu den Konstituenten der (damals herrschenden) Tonalität, ebenso wie der Kontrapunkt (im Schenkerschen Sinne als Grundlage der Mehrstimmigkeit), die Akkorde und Akkordstufen, die Stimmführung, die Darstellung einer übergeordneten Tonart sowie eine bestimmte Art der Metrik (die der Darstellung der tonalen Verhältnisse dient). Für sich genommen lassen sich alle diese Momente auch in der zweiten Hälfte des 19. Jahrhunderts beobachten. In Debussys Klavierstück The little Shepherd etwa erkennen wir dissonante Klänge,

8 Vgl. den Titel des Buchs von Bernhard Haas Die neue Tonalität von Schubert bis Webern. 
die sich auflösen, Akkorde, die sich zu Kadenzen zusammenschließen, Quintfälle im Bass und lineare Anschlüsse in der Oberstimme, Akkordfolgen, die sich zu A-Dur oder E-Dur verbinden, und Ereignisse, die ein Gefühl für den 4/4-Takt hervorbringen. Und doch ist nichts mehr so, wie es einmal gewesen ist: War die Darstellung einer Tonart für eine Komposition des 18. Jahrhunderts grundlegend, so geschieht sie bei Debussy optional. Sie ist eine unter vielen Möglichkeiten, Tonfelder zu artikulieren, und sie wird gewählt, um bestimmte Klangeigenschaften hervorzurufen. ${ }^{9}$ Ebenso kann Debussy - um ein weiteres Beispiel zu nennen - in seiner Musik einen Takt deutlich machen, oder er kann den Eindruck von Taktmetrik vermeiden. Was er wählt, hängt vom gewünschten musikalischen Charakter der jeweiligen Stelle ab, und wenn Debussy innerhalb einer Komposition zwischen taktgebundenen und ungebundenen Phrasen oder zwischen lokaler Tonartdarstellung und moderner Harmonik wechselt, wechselt er nicht das System des musikalischen Zusammenhangs, sondern er nutzt die Möglichkeit, innerhalb eines einzigen Systems sowohl spezifisch neue als auch traditionelle Konstellationen zu generieren. Somit lässt sich sagen, dass in der Tonfeldmusik aus den ehemaligen Konstituenten des musikalischen Zusammenhangs Mittel der Tonfelddarstellung geworden sind.

\section{Stimmführung und Rhythmus}

Die Tonalität, die gewöhnlich als die traditionelle angesehen wird und von der das Paradigma der sharmonischen Tonalitätı abgeleitet wurde, ist in etwa diejenige des späten 17. bis frühen 19. Jahrhunderts. ${ }^{10}$ Sie basiert - wie bereits angedeutet - unter anderem auf Stimmführung. Dies meint, dass Töne als Teilmomente von Stimmen aufeinander bezogen werden. Eine Stimme wiederum ist eine Funktion der Einheit von Tönen im Nacheinander. Diese Einheit manifestiert sich an Strukturen eigener Art, die von harmonischen Strukturen zu unterscheiden sind (sie heißen bei Schenker beispielsweise `Züge` oder `Brechungen`). In der Schenkerschen Funktionalität bilden Stimmen die Grundlage des musikalischen Zusammenhangs auf allen Schichten einer Komposition. Deswegen gibt es neben den satztechnischen Stimmen, die in der Partitur stehen, strukturelle Stimmen von unterschiedlicher Reichweite. Der Gesamtzusammenhang einer Komposition ist das umfassende Gefüge, in dem sämtliche Töne in vielfältiger Weise sowohl auf diverse Stimmen als auch auf Akkordstufen bezogen sind.

Was bedeutet es, wenn Bernhard Haas behauptet, dass die Tonfeld-Musik keine Stimmen kennt? ${ }^{11}$ Es bedeutet, dass Stimmführung ein Phänomen des Vordergrundes (oder der vordergründigen Schichten) ist. Stimmen (in dem Sinne, wie man von erster Oboe oder zweiter Trompete spricht) und Stimmführungsereignisse (etwa die charakteristische Polyphonie bei Wagner, Strauss und Schönberg) gibt es in der Partitur (und

9 Auch die Tonart E-Dur zu Beginn von Bruckners 7. Symphonie erscheint (in der speziellen Ausgestaltung mit den quintverwandten Durdreiklängen E, H, Fis und C, zahlreichen Quartvorhalten und einer tiefen Melodie in den Violoncelli bei gleichzeitigem Fehlen einer Bassstimme) als eines unter mehreren Mitteln, eine Atmosphäre von Stille, Glanz und Feierlichkeit zu erzeugen. Die Konstruktion des Satzganzen hingegen hat mit der traditionellen Tonart E-Dur sehr wenig zu tun.

10 Eine präzise Zeitangabe nach hinten ist nicht möglich, weil der Übergang zur Tonfeld-Musik fließend erfolgte und beide Tonalitäten teilweise nebeneinander bestanden.

11 Haas 2004, 70. 
vielleicht in etwaigen vordergründigen Schichten), nicht aber in mittel- und hintergründigen Schichten. Dieser Umstand bleibt nicht ohne Folgen für die Analyse. Erstens können Töne zu einem Tonfeld gehören, die unterschiedlichen Stimmführungszusammenhängen entstammen, und zweitens müssen umgekehrt auch vordergründige Stimmen in einer anderen als der gewohnten Weise interpretiert werden.

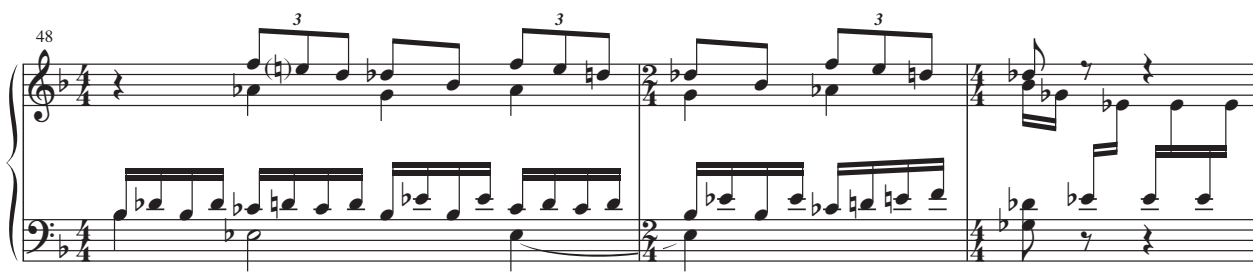

Beispiel 8: Claude Debussy, The snow is dancing, T. 48-50

In Debussys Klavierstück The snow is dancing könnte man in den Takten 48/49 im traditionellen Sinne fünf Stimmbewegungen ausmachen. Neben der Melodie im ıSopranı, dem Quintfall im `Bass` und der Wechselnotenbewegung as-g im >Altı lässt der >Tenor` eine latente Zweistimmigkeit erkennen: Eine obere sStimme beschreibt die Bewegung $d e s$ - $d$-es- $d$-es, eine untere eine parallele Wechselnotenbewegung ces- $b$ zum $>$ Altı. Die Interpretation dieser Stimmbewegungen als Prolongation einer Harmonie geschieht mit den traditionellen Kategorien des Kontrapunkts: Demnach würde es sich in den Takten 48 und 49 um das Auskomponieren eines Dominantseptakkordes auf es handeln, weil die Töne auf der zweiten und vierten Zählzeit in allen Stimmen - mit Ausnahme des `Basses` - als Nebennoten- oder Durchgangsnoten zu harmonieeigenen Tönen erscheinen (der Ton $e^{2}$ im `Sopran` wäre ein Durchgang zweiter Ordnung). Der Aspekt, auf den es mir in diesem Beispiel ankommt, betrifft die Rolle des Tones es ${ }^{1}$ im Tenor: Er wäre im Lichte dieser Interpretation als Bestandteil der Linie des- $d$-es anzusehen.

Aus der Perspektive der Tonfeld-Theorie heraus erscheint es allerdings äußerst fragwürdig, noch bei Debussy Vordergrundstimmen auf der Basis kontrapunktischer Kategorien aus einer mittelgründigen Akkordstufe herzuleiten. Eine andere Interpretation liegt näher: Die Takte 48/49 dienen dem Übergang zwischen zwei Tonfeldern. Ein früheres Tonfeld, eine Funktion mit den Grundtönen $d / f / a s / h$, überschneidet sich mit einem Ton es, der das spätere Tonfeld ankündigt, das in Takt 50 beginnt. Demnach gehören die Töne $d^{1}$ und $e s^{1}$ nicht demselben Tonfeld an, obwohl sie auf einer Linie liegen. Die Vereinigung zu einer vordergründigen Stimme ist funktional als Vermischung aus Tönen unterschiedlicher Tonfelder zu verstehen. Dass Debussy sie überhaupt im Vordergrund verbindet, ist dem Charakter der daraus resultierenden Spielfigur geschuldet.

Dass die Interpretation nach Tonfeldern eine gegenüber der Tradition veränderte Wahrnehmung der Tonbeziehungen impliziert, wird insbesondere am Verhältnis zwischen Leittönen und Grundtönen sowie Durchgangs- bzw. Wechselnoten und Hauptnoten deutlich, die nach traditionellen Kategorien des Kontrapunkts notwendig nacheinander erklingen. Wie der Leitton in den Grundton übergeht (und danach aufhört zu 
existieren), so würde - traditionell verstanden - der Ton $d$ (als harmoniefremder Durchgang) in den Ton es (als harmonieeigenem Ton) übergehen und in diesem verschwinden. Die Tonfeld-Theorie legt jedoch nahe, die Abfolge der Töne nicht als Übergang, sondern als äußerlichen Wechsel aufzufassen. Beide Töne bleiben dem Tonfeld erhalten, auch wenn in jedem Augenblick jeweils einer von beiden nicht erklingt.

Noch allgemeiner gesprochen, setzt die Theorie der Tonfelder eine gegenüber der straditionellen ‘ Tonalität veränderte Funktion der Metrik und des Rhythmus' für den musikalischen Zusammenhang voraus. Die erwähnten kontrapunktischen Kategorien, aber auch die erwähnten Strukturen der Stimmführung (beispielsweise ein Quintzug) basieren auf dem Nacheinander der Ereignisse, sie setzen eine Reihenfolge der beteiligten Töne voraus. Metrik und Rhythmik haben in der traditionellen Tonalität unter anderem auch die Funktion, dieses notwendige Nacheinander zu artikulieren. Würde dieses aufgehoben, würde zugleich der musikalische Zusammenhang aufgehoben. Die Reihenfolge hingegen, in der die Töne eines Tonfeldes erscheinen, unterliegt nicht generellen, sondern singulären Regeln. Die metrische und rhythmische Behandlung eines Tonfeldes dient in erster Linie dazu, das Tonfeld in einer bestimmten Art in Bewegung zu setzen. Das konkrete Nacheinander wäre nicht in der Struktur, sondern im gewünschten Charakter des Ereignisses begründet. ${ }^{12}$ Die veränderte Bedeutung der `Zeitlichkeit lässt in einer TonfeldKomposition Phänomene entstehen, die es in dieser Weise zuvor nicht geben konnte.

Von der Überschneidung zweier Tonfelder war bereits im letzten Beispiel die Rede. In Et la lune descend sur la temple qui fut (Beispiel 6) erscheinen - anders als zuvor - die tiefen Töne e und $h$, die strukturell zu den ersten Takten der Komposition gehören, erst in Takt 6. Von da an bleiben sie liegen, obwohl ihr `Familien- Tonfeld bereits verklungen ist. Stattdessen grundieren sie Akkordfolgen, die ihrerseits neue Tonfelder artikulieren. Bemerkenswert ist der moderne Effekt der Tonfeld-Überlagerung. Im traditionellen Sinne würde der Bass die herrschende Harmonie definieren, und die Töne der übrigen Stimmen, die von der definierten Harmonie abweichen, müssten im kontrapunktischen Sinne als Neben-, Wechsel- oder Durchgangstöne (bzw. -harmonien) betrachtet werden. Bei Debussy existiert diese Art von Hierarchie jedoch nicht. Das Zugleich mehrerer Ebenen, das Zusammengesetzte aus Ereignissen unterschiedlicher struktureller Herkunft teilt sich über das Hören mit. Auch hier helfen die Klangfarben (bei Debussy ist die Tiefe eines Klaviertons ein Moment seiner Klangfarbe), die Schichten voneinander zu unterscheiden. Indem man sie als verschieden hört, bezieht man sie einerseits aufeinander, ohne sie andererseits zu einer (traditionellen) Einheit zu verbinden.

\section{Brahms, Intermezzo op. 76,7}

Die Behauptung, dass im Intermezzo op. 76,7 von Johannes Brahms ein Konstrukt wirkt, ist nicht selbstverständlich. Denn das Stück entspricht - anders als Kompositionen von Bruckner, Debussy oder Schönberg - nicht den typischen Erwartungen an eine Tonfeld-

12 Auch das gelegentlich zu beobachtende Phänomen, dass die sukzessive Auffüllung eines Tonfeldes als zielgerichteter Prozess erscheint, beruht nicht auf einer generellen Eigenschaft von Tonfeldern, sondern auf einer speziellen Inanspruchnahme. 

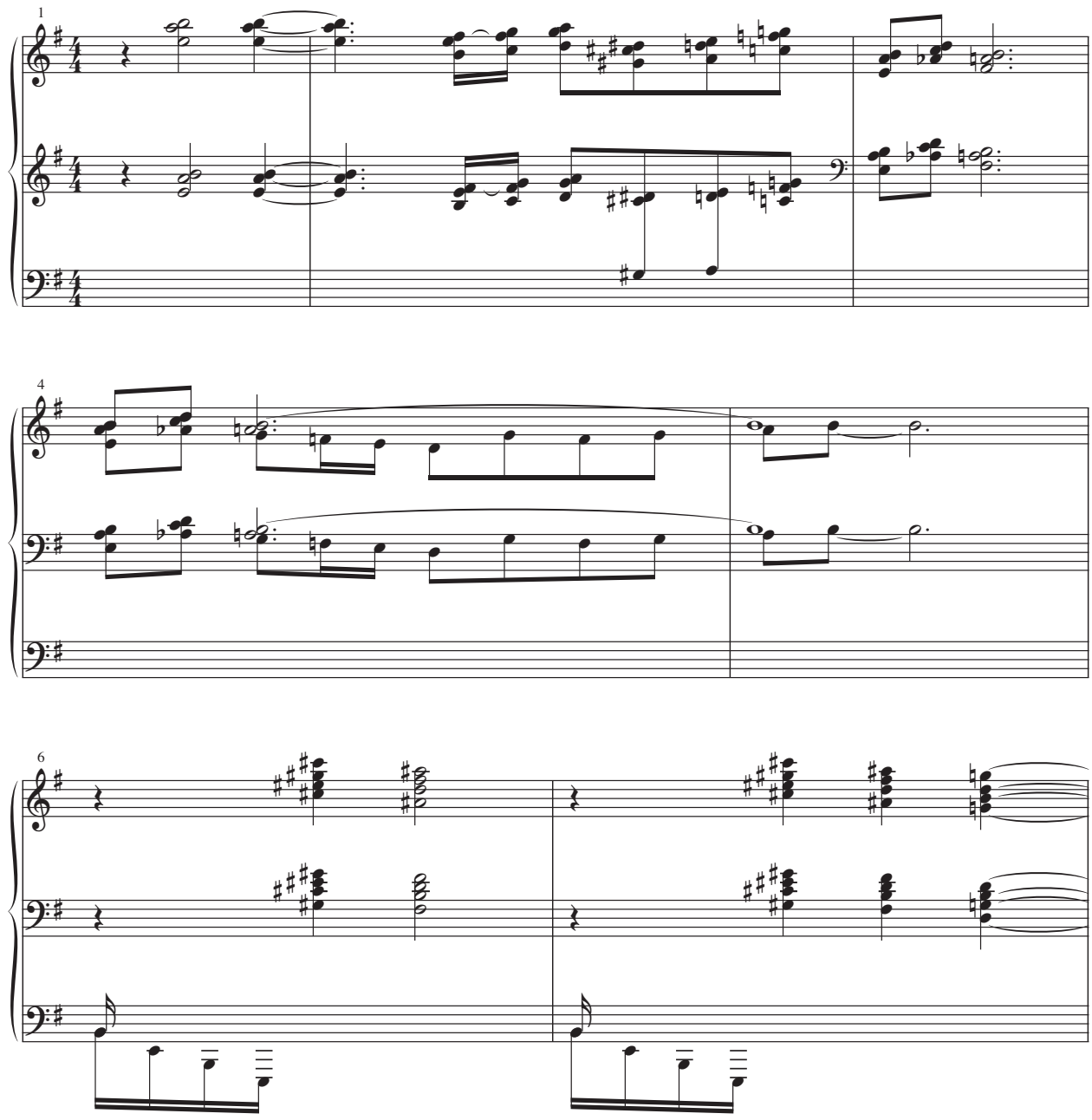

Beispiel 9: Claude Debussy, Et la lune descend sur la temple qui fut, T. 1-7

Komposition. Die Komposition steht in a-Moll. Die Tonart existiert nicht nur gelegentlich als lokale Tonart, sondern durchaus im traditionellen Sinne als System, das sich im Satzganzen entfaltet. Erkennbar ist dies beispielsweise daran, dass die Haupttonart a-Moll und die Seitentonart C-Dur zentrale Stellen der Formbildung besetzen. Diese traditionelle Tonartendisposition wird überdies im zweiten Teil - wiederum ganz im traditionellen Sinne - durch eine lineare Bassbewegung vermittelt, die (zusammen mit den übrigen Stimmen des Tonsatzes) Akkorde herbeiführt, deren Durchgangsfunktion als Klangeigenschaft fühlbar ist.

Bei dem fraglichen Tonfeld im Intermezzo handelt es sich um das Konstrukt la. Es findet sich - auf zwei Stellen verteilt - im zweiten Formabschnitt (T. 9-16, dort T. 13) und 
am strukturellen Schluss (T. 36b/37).$^{13}$ Diese Interpretation bereitet in zweierlei Hinsicht Probleme:

1. Tonart und Konstrukt scheinen einander ausschließen..$^{14}$ Ein Konstrukt ist ein Tonfeld, das in aller Regel Klangwirkungen hervorruft, die im Sinne traditioneller Tonalität unverständlich wirken. Entweder - so könnte man denken - suspendiert das Konstrukt also die traditionelle Tonart, oder die traditionelle Tonart verhindert, wenn sie kontinuierlich besteht, dass ein Konstrukt entstehen kann. Bei Brahms aber existieren a-Moll und Konstrukt gleichzeitig, ohne dass ein Moment das andere auslöschen würde.

2. Überdies ist das Konstrukt über die Komposition verteilt. Wie soll es möglich sein, zwei entfernte Stellen, die in mancher Hinsicht sehr unterschiedlich angelegt sind, als gemeinsame Darstellung eines Konstrukts aufeinander zu beziehen?

Das Konstrukt la besteht aus den drei Quinten a-e, $f$-c und cis-gis. ${ }^{15}$ Der Quinte a-e kommt wegen der Tonart a-Moll ein Vorrang zu. In der Schicht des Hintergrundes wird die Quinte a-e an den beiden Stellen mit jeweils einer anderen Quinte kombiniert: $f$ - $c$ und a-e erscheinen im Mittelteil, a-e und cis-gis in der Coda. Mittelgründig werden die Quinten-Paare jeweils zu fünftönigen Konstrukten erweitert. Im Mittelteil tritt gis hinzu, in der Kadenz c (Beispiel 10).

Die beiden fünftönigen Konstrukte, die hintergründig ein einziges umspannendes Konstrukt bilden, gehen auf jeweils eigene Art aus dem Satzzusammenhang hervor. Im Mittelteil (von Takt 12 an) steht das Tonfeld inmitten einer chromatischen Durchgangsbewegung des Basses. Wenn man die Töne des Tonsatzes als Teilmomente struktureller Stimmen liest, dann lassen sich vor allem ein Liegeton $e^{2}$ im 'Sopran E-F-Fis-G voneinander unterscheiden. Darüber hinaus erkennt man einen angedeuteten ‘Altı, der dem Bass - für drei Stationen - in parallelen Terzen folgt (gis $\left.-a^{1}-a^{1}-\left[a s^{1}\right]\right)$. Eine Tenorstimme ließe sich in der Tonfolge $h-c^{1}-c^{1}-c^{1}$ erblicken, wenn man die Quintparallele zum Bass nicht scheut. Die Töne dis ${ }^{2}$ und gis ${ }^{1}$ wären als Wechsel- bzw. Nebennoten zu $e^{2}$ bzw. $a^{2}$ zu verstehen. Das erste fünftönige Konstrukt entsteht also in Takt 13, wenn - traditionell analysiert - der Liegeton $e^{2}$ mit dem Durchgangston $F$, der angekoppelten Note $c^{2}$, der Nebennote gis ${ }^{2}$ sowie deren `Auflösung` $a^{2}$ zusammentrifft (Beispiel 11).

Das zweite fünftönige Konstrukt entsteht am ıstrukturellen Schluss`, an der Dominante (E-Dur-Septakkord) und der Tonika (a-Moll-Grundakkord). Zu beachten ist hier die partielle Analogie der Akkorde. Beide Akkorde werden im `Alt - jeweils auf dem zweiten Achtel der Vierergruppen - mit einer unteren Nebennote angereichert. Auf der Pänultima erscheint $c s^{1}$ vor der Septime $d^{1}$, auf der Ultima $h$ vor der Terz $c^{1}$. Dadurch

13 Auf die mit dem Konstrukt verwandte Stelle in den Takten 27-29 wäre gesondert einzugehen.

14 Vgl. den Beitrag von Markus Sotirianos in dieser Ausgabe.

15 Ich glaube nicht, dass das Konstrukt bereits im Hintergrund der Komposition angelegt ist. Von welcher Schicht an es allerdings auftaucht, muss vorläufig offen bleiben. Wenn im folgenden Text von Hintergrund und Mittelgrund die Rede ist, so geschieht dies provisorisch. Gemeint ist mit dem Hintergrund die einfachste Schicht, auf der das Konstrukt zum ersten Mal auftaucht. Der Mittelgrund bezeichnet die nächste ausführlichere Schicht. 

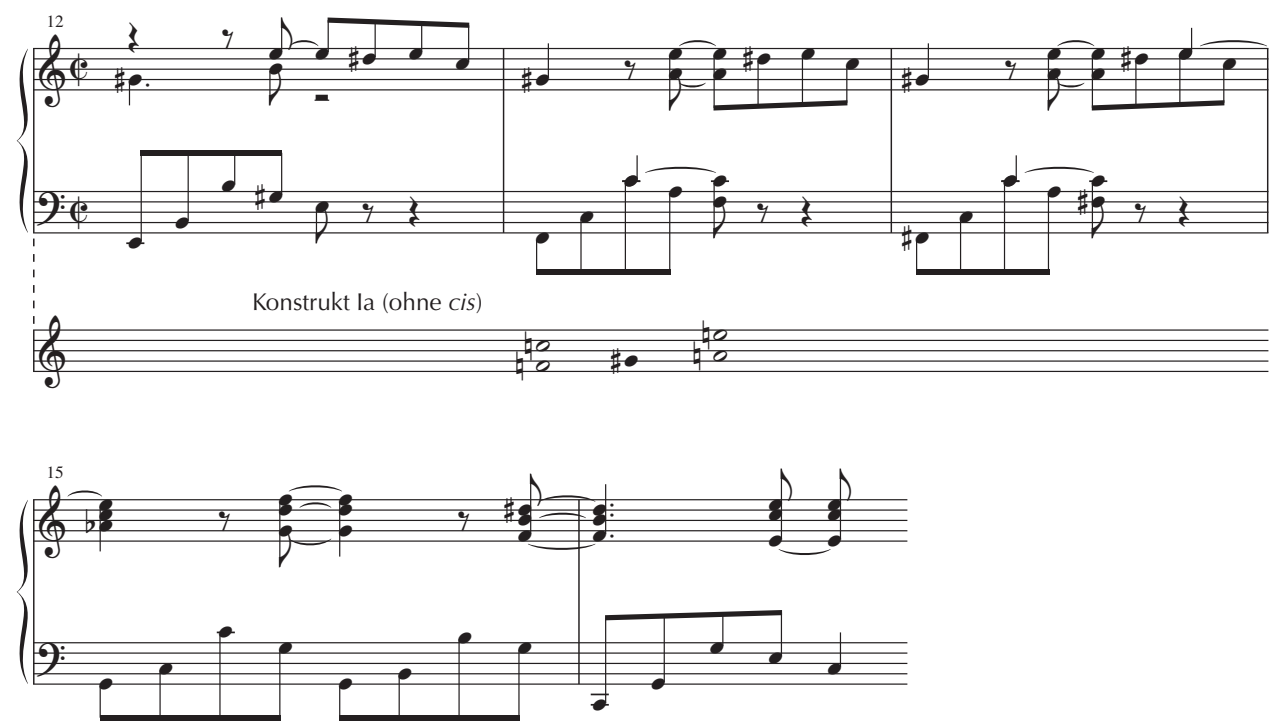

Beispiel 10: Johannes Brahms, Intermezzo op. 76,7, T. 12-16 (Mittelteil)

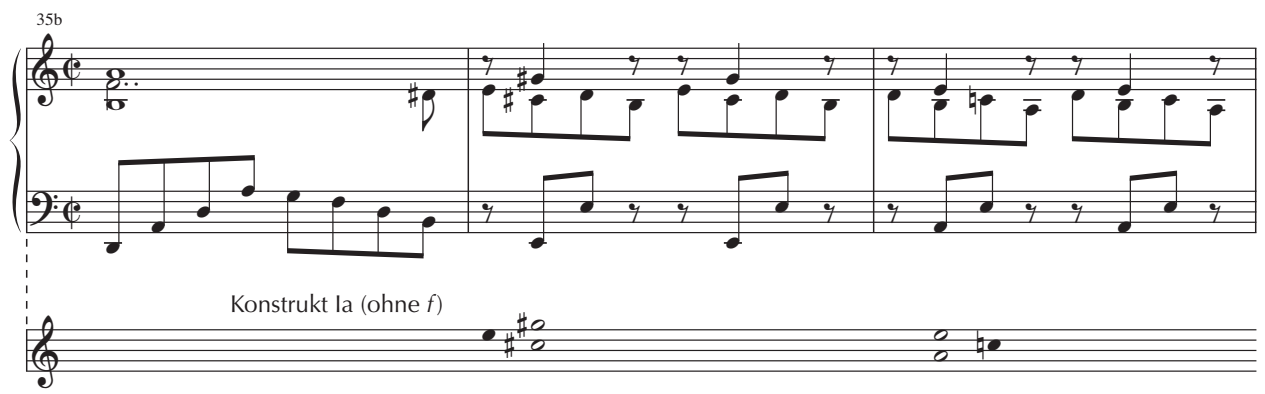

Beispiel 11: Johannes Brahms, Intermezzo op. 76,7, T. 35b-37 (struktureller Schluss)

dass außerdem der Leitton gis ${ }^{1}$, der in der Oberstimme liegt, nicht zum Grundton $a^{1}$ aufgelöst wird, sondern zum Quintton $e^{1}$ der Tonika abspringt, entsteht eine Situation, in der auf den analogen Positionen (2. Achtel der Gruppen) die Quinten cis-gis und a-e erklingen. Zur hintergründigen Quinte cis-gis lässt sich im Mittelgrund der vorangehende Ton $e^{1}$ rechnen, zur Quinte a-e der folgende Ton $c^{1}$.

Zunächst kann die zweite Frage beantwortet werden. Die Möglichkeit, die beiden analysierten Stellen als Ausdruck eines Tonfeldes aufeinander zu beziehen, gründet auf der gemeinsamen ssinistren Klangwirkung, die beide Teil-Konstrukte unabhängig von der Unterschiedlichkeit des Kontextes, in dem sie stehen, hervorbringen. Der Klang zu Beginn von Takt 13 (beim Zusammentreffen von gis mit der Quinte $f$-c), auf den der Klang auf dem vierten Achtel zu beziehen ist, wirkt ebenso befremdend wie die Kom- 
bination des Leittons gis mit dem Ton cis, die wiederum mit dem a-Moll-Akkord zusammen zu hören ist. Dass die Analogie der Klangwirkungen die Stellen aufeinander beziehbar macht, unterstreicht das Gesagte: dass die Töne der Tonfelder als Klänge aufeinander bezogen werden, nicht durch Stimmführungszusammenhänge oder durch eine lokale Tonart.

Wie genau aber werden in Brahms' Komposition die Tonfelder artikuliert? Wie kann sich eine Konstellation aus Tönen zu einem Tonfeld zusammenschließen und gegen die (hier sehr starken) Zusammenhänge von Stimmführung und lokaler Tonart durchsetzen? Die Konstruktwirkungen werden nicht durch die Grundkonstruktion des Tonsatzes, sondern durch Details der zeitlichen Koordination hervorgerufen. Beim ersten Teil-Konstrukt bilden Position und melodische Einbindung des Tones gis die entscheidenden Momente. Zum einen folgt gis in der Oberstimme (wie bereits an allen ähnlichen Stellen zuvor) den Tönen e und c, zum andern trifft der sunvorbereitete Vorhaltı gis am Taktanfang mit der Quinte $f-c$ in der linken Hand zusammen. Die rhythmisch-metrische Einrichtung erfolgt so, dass sich gis melodisch zu einem übermäßigen Dreiklang c-e-gis und zugleich harmonisch zu einem scheinbaren f-Moll-Dreiklang verbindet. Der Tonort gis/as wird als gis und as zugleich gehört (Beispiel 12). ${ }^{16}$

Die Konstruktwirkung nähme ab, würde man (wie in Beispiel 12b) dem Ton gis einen vollständigen a-Moll-Dreiklang vorausgehen lassen (so dass es zur sukzessiven Bildung eines übermäßigen Dreiklangs nicht kommen kann). Würde man ihn (wie in Beispiel 12c) an das Ende von Takt 12 vorverlegen (an diejenige Stelle, an die er strukturell gehört) und überdies den Dominantklang, der im gesamten Takt 12 harmonisch ıgemeint ist, von harmoniefremden Tönen befreien, dann bliebe von der Konstruktwirkung nichts mehr übrig.

Das zweite Teil-Konstrukt fällt klanglich milder aus. Hier entsteht für einen Augenblick ein scheinbarer cis-Moll-Akkord, der auf das folgende a-Moll bezogen werden kann. Die Kombination cis-Moll - a-Moll reicht für eine Konstruktwirkung aus. Zu einer starken Wirkung wie im zweiten Formabschnitt kommt es allerdings nicht, weil der Ton c zwischen den Quinten a-e und cis-gis immer nur als c, nicht aber auch als his verstanden werden kann.

Mit andern Worten: Die Ursache für die Konstruktwirkungen liegt letztlich darin, dass Brahms die fundierende Bedeutung der Rhythmik für das konstitutive Nacheinander bestimmter Töne partiell suspendiert. Töne, die um der traditionellen Verständlichkeit willen auseinander gehalten werden müssten (gis, $f$ und c sowie cis, gis und e), werden übereinander geschoben. Was als Merkmal der Motiv- und Melodiebildung von Beginn des Stücks an hervorsticht (die Verschiebung zahlreicher Töne von ihrem funktional `korrekten< Platz), steht auch im Dienst der Tonfelddarstellung. Dennoch bleibt die Verschiebung der Töne in dieser Komposition (vergleicht man sie mit dem ungleich radikaleren Anfang des Intermezzos op. 119,1) als extreme Inanspruchnahme von Stimmführungszusammenhängen verständlich.

16 Zur Ambivalenz von gis und as vgl. den Beitrag von Dres Schiltknecht in dieser Ausgabe. 
Original

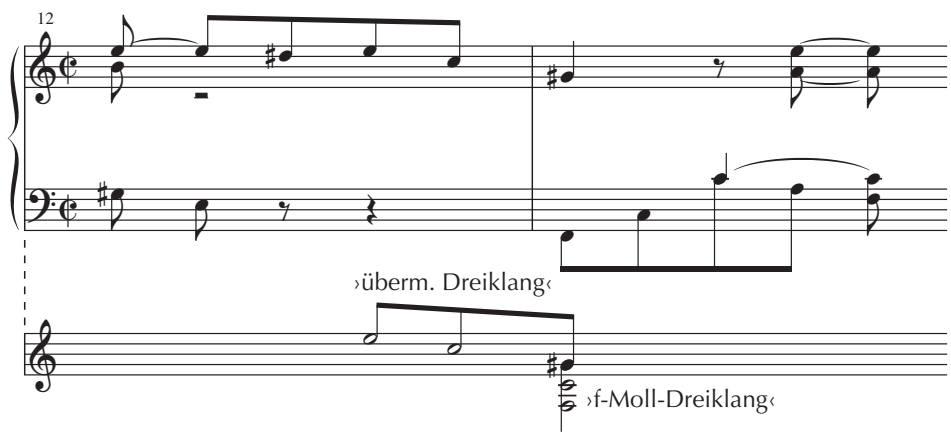

Variante 1

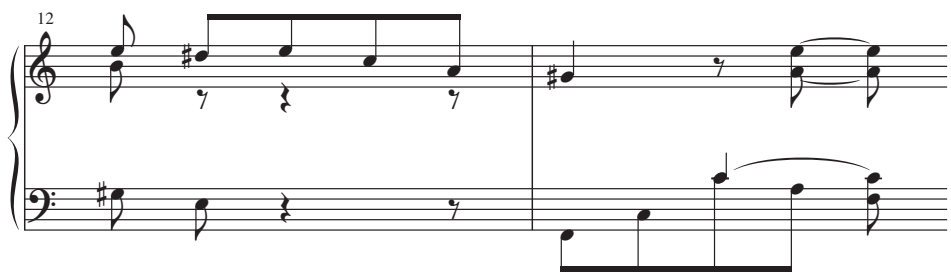

Variante 2

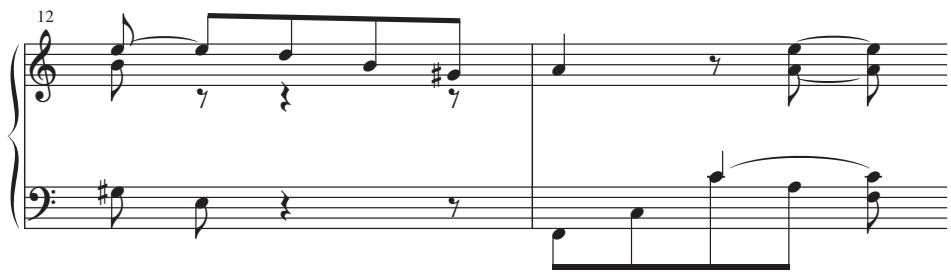

Beispiel 12: Johannes Brahms, Intermezzo op. 76,5, T. 12 f.

(Original und zwei Varianten)

\section{Claude Debussy, The little Shepherd}

Im Gegensatz zu Brahms' Klavierstück weist dasjenige Debussys alle äußerlichen Merkmale einer Tonfeld-Musik auf. Der Tonsatz enthält kaum Phänomene, die traditionelle Strukturen andeuten. Die Tonfelder entstehen nicht indirekt durch metrische Detailabweichungen, sondern ergeben sich unmittelbar aus den Melodie- und Zusammenklangsbildungen. Der Versuch einer vollständigen Analyse stößt allerdings auf neue Probleme: Welche Ereignisse sollen welchen Tonfeldern auf welchen Schichten zugeordnet werden, und welche Art von 'Logikı liegt in der Reihung, Verschränkung und Vermischung unterschiedlicher Tonfeld-Typen? 


\section{Gliederung und Charaktere}

Das Klavierstück besteht aus drei 'Strophen` und einer (um die ersten sechs Takte verkürzten) Wiederholung der ersten Strophe. Ungeachtet der melodischen und harmonischen Unterschiede im Detail kann man vergröbernd sagen, dass jede Strophe dieselbe Abfolge von drei Ereignistypen aufweist: eine unbegleitete Melodie, eine begleitete Melodie und eine Art von Kadenz, in die die begleitete Melodie mündet und die 'Strophe` beschließt. Jedem Ereignistyp entspricht ein Strophen-Teil.

\begin{tabular}{|c|c|c|c|c|c|c|c|c|c|c|c|}
\hline \multirow{2}{*}{$\begin{array}{l}\text { Strophe } \\
\text { Teile }\end{array}$} & \multicolumn{3}{|l|}{1} & \multicolumn{3}{|l|}{2} & \multicolumn{3}{|l|}{3} & \multicolumn{2}{|c|}{1 verkürzt } \\
\hline & $\mathrm{a}$ & $b$ & C & $\mathrm{a}$ & $b$ & C & $a$ & $b$ & C & b & C \\
\hline Inhalte & Melodie & $\begin{array}{l}\text { Begleitete } \\
\text { Melodie }\end{array}$ & Kadenz & Melodie & $\begin{array}{l}\text { Begleitete } \\
\text { Melodie }\end{array}$ & Kadenz & Melodie & $\begin{array}{l}\text { Begleitete } \\
\text { Melodie }\end{array}$ & Kadenz & $\begin{array}{l}\text { Begleitete } \\
\text { Melodie } \\
\text { (2. Teil) }\end{array}$ & Kadenz \\
\hline Takte & $1-4$ & $5-8$ & $9-11$ & $12-13$ & $14-15$ & $16-18$ & $19-20$ & $21-23$ & $24-26$ & $27-28$ & $29-31$ \\
\hline
\end{tabular}

Abb. 1: Claude Debussy, The little Shepherd (Formübersicht)

Ästhetisch relevant (und typisch für Debussy) ist die Tatsache, dass die analoge Abfolge der Ereignistypen von einer abweichenden Abfolge musikalischer Charaktere kontrapunktiert wird, so dass >dieselben Ereignistypen in jeder Strophe anders charakterisiert erscheinen. ${ }^{17}$ Die zweite Strophe ist die einzige, deren Klangcharakter über alle drei Unterabschnitte hinweg stabil bleibt. Sie wirkt in sich ruhend, mild, ohne Ecken und Kanten, weist aber auch keine 'glänzenden`Stellen auf. In der dritten Strophe hingegen prallen Ereignisse großer Gegensätzlichkeit aufeinander. Die verhaltene Melodie zu Beginn steht in schroffem Kontrast zum glänzenden `Dis-Durı-Akkord am Ende (T. 24-26), dem bemerkenswertesten Klang des Klavierstücks (er bildet zusammen mit dem vorangehenden rais-Molk-Akkord den Höhepunkt der Komposition). Die rahmenden Strophen 1 und 1' vereinigen wie die dritte Strophe Gegensätze, doch der Unterschied der Charaktere ist geringer, die Abfolge wirkt ausgewogener. ${ }^{18}$ Im Ensemble dieser Charaktere stellt die erste Strophe die Exposition des Ganzen dar, die zweite eine ruhige Mitte und damit zugleich das retardierende Moment vor der dritten Strophe, in der die extremsten Charaktere des Stücks hörbar werden.

\section{Die Kadenzen}

Die vier Kadenzen, mit denen jede der drei Strophen sowie die unvollständige Wiederholung der ersten Strophe schließt, lassen lokale Tonarten deutlich werden, ohne allerdings das traditionelle System der Tonalität zu restituieren. Diese doppelte Bestimmung (als traditionelle Kadenzen und als mögliche Artikulation von Tonfeldern) lässt sich satztechnisch veranschaulichen.

17 Die folgende Beschreibung der Charaktere geht vom Ergebnis dieser Untersuchung aus. Sie gibt nicht einen spontanen oder unvoreingenommenen Eindruck von Klangwirkungen wider, dessen $>$ Richtigkeit` durch eine anschließende Tonfelder-Analyse bewiesen würde. Tatsächlich hat sich der Eindruck der Klangwirkungen in Auseinandersetzung mit der Interpretation der Tonfelder herausgebildet. 


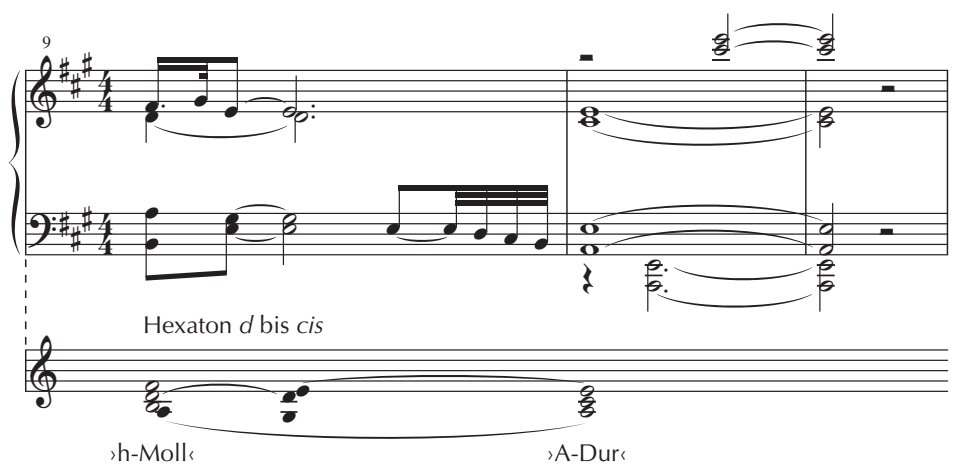

Beispiel 13: Claude Debussy, The little Shepherd, T. $9 \mathrm{ff}$. (Notentext und Analyse)

Traditionelle Momente der Kadenzen in den Abschnitten 1, 2 und 4 sind jeweils der doppelte Quintfall (beispielsweise in Takt 9-11: h-Moll - E-Dur [mit Septime] - A-Dur) sowie zwei angedeuteten Klauseln: eine Bassklausel und eine Sopranklausel in der >Tenorstimme $\triangleleft .{ }^{19}$ Auch die Disposition der Kadenzen als A-Dur, E-Dur und wiederum A-Dur lässt an eine traditionelle Komposition in A-Dur denken (dieser Eindruck selbst dürfte ästhetische Absicht sein, s. u.).

Dafür dass man die Kadenzen besser als zitathafte Anleihen an Vergangenes auf dem Boden einer neuen Tonalität betrachtet, spricht zweierlei. Erstens: So deutlich die Kadenzen für sich auf traditionelle Tonarten verweisen, so wenig nehmen die übrigen Takte Bezug darauf. Viele Passagen sind unbestimmt oder nur gewaltsam auf eine Tonart zu beziehen (etwa Takt 5). ${ }^{20}$ Traditionelle Tonalität erschöpft sich aber nicht in lokaler Tonikalität, sondern stellt ein umfassendes Bezugssystem dar, das durch sämtliche Teilmomente des Satzes konstituiert wird (ganz gleich welche Funktion sie darin einnehmen). Zweitens lassen Details der satztechnischen Darstellung an den Kadenzen untraditionelle Klangeigenschaften hervortreten. Zu solchen Details gehören bei der ersten Kadenz in den Takten 9-11 etwa die Quinten an den Taktanfängen: $h$-fis und a-e. Deren analoge Positionen in den Außenstimmen (die Quinte ist bei A-Dur wegen der Bewegung in der tiefsten Stimme besonders deutlich) sowie in den Oktavlagen machen die Akkorde

18 Bemerkenswert ist beispielsweise, dass die Abschluss-Kadenz der ersten Strophe im Kontext der vorgegangenen >dunklen Ereignisse glänzender wirkt als die analoge Kadenz der zweiten Strophe, die sneutralen Ereignissen folgt.

19 Der Quintfall am Ende von Abschnitt 3 - der dritten Strophe - wirkt wegen der Dur-Moll-Konstellation ais-Moll - Dis-Dur und des Lagenwechsels - die Akkorde erscheinen in zwei verschiedenen Oktavlagen - vergleichsweise untraditionell. Im übrigen handelt es sich aus Sicht der Tonfeld-Theorie bei den beiden Zusammenklängen nicht um Dreiklänge (s. u.).

20 Der Klangcharakter des Taktes 5 wird durch die große Sekunde $f$-g und durch die Folge der kleinen s Sexten $f$-cis und gis-e geprägt (die zu einer Funktion gehören). Nur mit Mühe lässt sich der Takt auf die Tonart A-Dur beziehen: beispielsweise als subdominantischer Akkord der II. Stufe $h$ - $d$-f-as (mit diversen Vorhalten: $g$ vor as in der Mittelstimme sowie cis vor $h$ und e vor $d$ in der Oberstimme), der zur V. Stufe als Moll-Akkord geht, oder als Wechsel zwischen Tonika und Dominante auf jedem Viertel (dabei wird die Tonika mit Sexte und Septime angereichert, die Dominante mit einer None). 
h-Moll und A-Dur unmittelbar aufeinander beziehbar. Neben dem doppelten Quintfall tritt so auch die Wirkung eines Hexatons $d$ bis cis hervor. Der E-Dur-Akkord (ohne Quinte), der das rahmende Hexaton zu einem Heptaton $d$ bis gis erweitert, vermittelt zwischen den Außenakkorden, und die Septimen, die h-Moll und E-Dur anreichern, machen die Quintenreihe fließender und lassen die Akkorde klanglich aufeinander abgestimmt wirken. ${ }^{21}$

Die hier behauptete Funktion der Kadenzen bedeutet nicht, dass die Komposition keinen Grundton besäße. Diesen gibt es durchaus, und er lautet sogar a. Aber dieser Grundton ist nicht der Grundton einer traditionellen, auf Stimmführung und Akkordfolgen basierenden Tonart, sondern einer, der primär durch die Konstellation der Tonfelder begründet wird ${ }^{22}$ (dass die durch Tonfelder begründete Tonalität wiederum in Kadenzen auf A-Dur und E-Dur einen traditionellen Widerhall findet, ist kein Zufall).

\section{Tonfelder und Skalen}

Dem Verlauf der Charaktere entspricht der Verlauf der Tonfelder. Wo der Charakter neutral ist oder ins Milde tendiert, erscheinen Quintenreihen, wo er unbestimmt wird, erklingen Funktionen, und wo er eine Schärfe erhält, Konstrukte. Wo Charaktere unverändert ausgehalten werden (wie in der zweiten Strophe), bleibt auch das Tonfeld unverändert. Wo rasche Wechsel der Charaktere zu beobachten sind (wie in der dritten Strophe), durchläuft das Geschehen eine Mehrzahl von Tonfeldern.

Wie in einigen anderen Kompositionen Debussys bis 1907 bilden die Quintenreihen die Basis des Formganzen. Funktionen und Konstrukte hingegen werden wie lokale Ereignisse in die Quintenreihen eingesprengt, ihre Reichweite beträgt manchmal nur einen oder zwei Takte. Der konstruktiven Bedeutung der Tonfelder entspricht, dass die Atmosphäre, die von Quintenreihen ausgeht, den Charakter der Komposition im Ganzen bestimmt, während die Charaktere von Funktionen und Konstrukten als lokale Kontraste fungieren.

Diejenigen Quintenreihen, Funktionen und Konstrukte, die einander ablösen, ähneln sich sehr, weil ihre Tonvorräte weitgehend übereinstimmen. Der Austausch weniger Töne (beim Übergang zwischen verschiedenen Tonfeld-Typen) bewahrt also einerseits

21 Auch der Blick auf die übrigen Stücke aus der Sammlung Children's Corner lässt erkennen, dass The little Shepherd nur eine unter verschiedenen Möglichkeiten nutzt, Tonfelder zu artikulieren. So wird eine traditionelle Tonart Es-Dur in Golliwogg's cake walk einerseits sehr viel deutlicher (durch die Konstellation der Stufen) und ausgedehnter (sie ist über ganze Taktgruppen hinweg konsequent erkennbar) auskomponiert, andererseits tritt der Zitatcharakter um so deutlicher hervor: Man könnte meinen, eine Parodie auf eine Tonart zu hören. Hingegen kommt das Klavierstück The snow is dancing gänzlich ohne Anleihen an traditionelle harmonische Muster aus. Alle diese Kompositionen aber gehören zu einer einzigen Sammlung. Wenn man nicht die absurde These verfechten möchte, Debussy habe in jedem seiner Stücke das System des musikalischen Zusammenhangs gewechselt, dann muss man davon ausgehen, dass sowohl die vermeintlich tonalen Stellen als auch die modernen gleichermaßen Artikulationen derselben Typen von Zusammenhängen sind.

22 Zur Konstitution des Grundtons a durch Tonfelder gehört beispielsweise der Umstand, dass die Schlussakkorde der ersten, dritten und vierten Strophe (A-Dur und Dis-Dur) zusammen eine sechstönige Funktion bilden. Weitere Umstände (von größerer Bedeutung) werden in den folgenden Abschnitten beschrieben. 
einen Großteil des Tonmaterials, löst andererseits aber einen verhältnismäßig starken Wechsel in der Klangwirkung aus, weil er den einen Tonfeld-Typ in einen anderen transformiert. Das Verhältnis der Tonfelder wird am besten sichtbar, wenn die Tonfelder als Skalen notiert werden (hier von $e^{2}$ aus abwärts). Das Heptaton $d$ bis gis aus den Takten 1-4 und die Funktion auf e/g/b/cis aus Takt 5 bilden zusammen vier Tetrachorde aus, die hinsichtlich ihrer Struktur übereinstimmen (da das Heptaton nur sieben Töne enthält, muss man von skonjunkten Tetrachorden ausgehen). Von den konkreten Tonhöhen her gleichen sich allerdings nur die oberen Tetrachorde (jeweils e- $d$-cis- $h)^{23}$, während das untere Tetrachord in der Funktion einen Halbtonschritt tiefer liegt als im Heptaton.

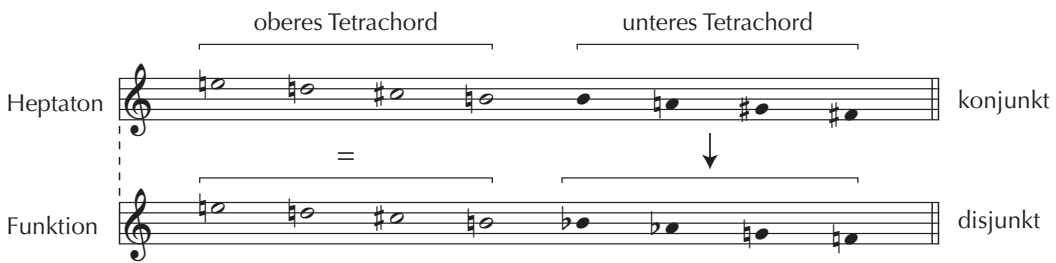

Beispiel 14: Vergleich Heptaton - Funktion

Vergleichbare andere Ähnlichkeiten, wie sie zwischen dem Heptaton a bis gis (T. 12-18), der Funktion $\mathrm{h} / \mathrm{d} / \mathrm{f} / \mathrm{gis}$ (angedeutetes Tonfeld in den Takten 19/20), dem harmonischen Oktoton a bis ais und dem Konstrukt Ilb bestehen, werden im Zusammenhang mit dem Beginn der 3. Strophe besprochen (vgl. dazu Beispiel 19).

Für mehrere Tonfelder dieser Komposition spielt die Auslassung eines Tons eine bedeutsame Rolle. Gleich zu Beginn des Stücks erscheint Heptaton $d$ bis gis ohne den Ton a (den Grundton der Komposition). Sein Fehlen erzeugt innerhalb einer skalenförmigen Anordnung eine smelodische Lücke` (hier eine kleine Terz gis- $h$ ), innerhalb einer Quintenanordnung eine sstrukturelle Lückes.
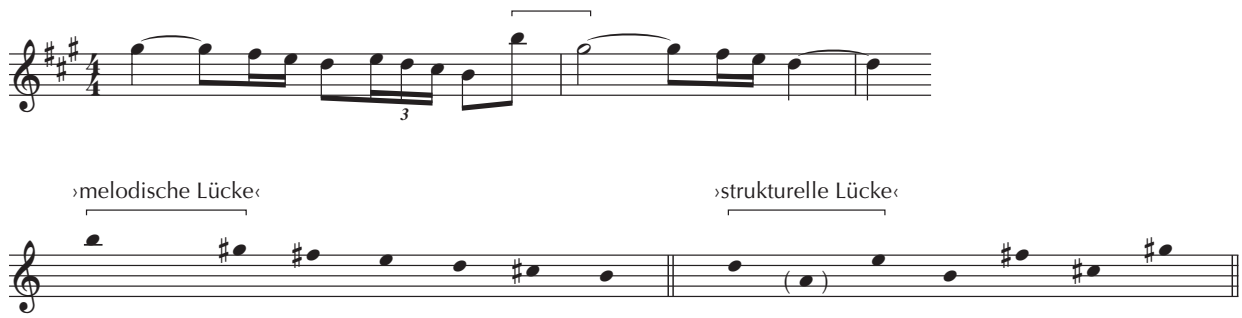

Beispiel 15: Claude Debussy, The little Shepherd, T. 1-4 (Notentext und Analyse)

23 Vgl. den Anfang des ersten Teils von La Mer mit ähnlichen Beziehungen: Das Tetrachord $h$-a-gis-fis (T. 8-11) gehört einerseits zu einem Heptaton $d$ bis gis (zunächst in den Takten 1-5 nur als Tetraton $h$ bis gis angedeutet), andererseits zur Funktion h/d/f/gis (Holzbläser, T. 6-8, und Englischhorn/Trompete, T. 9-14). An manchen Stellen sind der Funktion Töne anderer Tonfelder beigemischt. 


\section{Gesamtanlage}

Die Gesamtanlage des Stücks lässt sich am einfachsten erklären, wenn wir vom hintergründigen Tonfeld ausgehen und die wesentlichen mittelgründigen Erweiterungen benennen.

\section{Das Oktoton des Hintergrundes}

Den Hintergrund der Komposition bildet das Oktoton a bis ais. Es besteht aus den vier Quinten a-e, $h$-fis, cis-gis und dis-ais, die in eben dieser Reihenfolge durchlaufen werden: von der ersten Strophe an bis zum Höhepunkt in den Takten 24-26. Dabei finden sich die Quinten a-e und $h$-fis in den ersten beiden Strophen, die beiden übrigen Quinten cis-gis und dis-ais in der dritten. Die Oktavlage der Quinten im Diagramm entspricht der tatsächlichen Lage innerhalb des Stücks. Ich nenne diese Lage in Anlehnung an Heinrich Schenker die sobligate Lage` der Klänge (zu Abweichungen von der obligaten Lage s. u.).

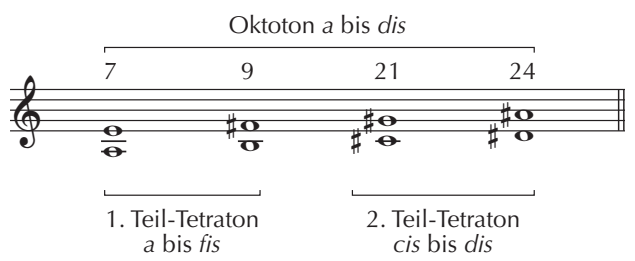

Beispiel 16: Claude Debussy, The little Shepherd (Hintergrund) ${ }^{24}$

Dass man ausgerechnet an diesen vier Quinten (in dieser Lage) das konstruktive Ganze des Klavierstücks festmachen kann, bedarf der Erläuterung. Dabei hilft der Hinweis auf einen besonderen Aspekt der Satztechnik: In den meisten Takten des Stücks erklingen keine Basstöne (Töne einer vordergründigen Bassstimme). Entweder ist die Melodie der rechten Hand unbegleitet (T. 1-4, 12/13 und 19/20), oder die Begleitung besteht aus linear bewegten Terzen in relativ hoher Lage; sie wirken mehr wie die Bewegungen von Mittelstimmen als wie die Töne eines Basses (T. 5/6, 8, teilweise 14/15, 22/23 und 28). Betrachtet man jedoch alle übrigen Takte (Takte, in denen eine Begleitung existiert, die nicht nur auf Terzen basiert), dann findet man darin beinahe ausnahmslos Basstöne (tiefste Töne, die von den höheren Tönen vertikal abgesetzt sind) mit einem Ton im Quintabstand darüber (Ausnahme bilden allein die `Dominantklänge` der `Kadenzen`; zu Takt 14 s.u.). Mit anderen Worten: Alle oder die meisten Klänge in diesen Takten basieren auf Quinten.

Die erste Quinte a-e in Takt 7 ist die erste Quinte des Stücks überhaupt (klanglich herausstechend durch das Unisono-e zwischen rechter und linker Hand). Sie bringt zum ersten Mal den Grundton a und damit den bis dahin tiefsten Ton der Komposition.

Die nächsten Quinten an den Anfängen der Takte 9 und 10 ( $h$-fis und a-e) grundieren die beiden erwähnten zentralen Akkorde der ersten Kadenz. Auch mit ihnen werden jeweils die bis dahin tiefsten Töne der Komposition erreicht. Zugleich entsteht durch die tiefe Oktavlage zum ersten Mal ein echter Basstoncharakter. Bis zum Ende der ersten

24 Die Taktzahlen beziehen sich auf das jeweils erste Erscheinen der Quinten. 
Strophe wird die erste Hälfte des hintergründigen Oktotons durchlaufen und damit das erste Teil-Tetraton des Hintergrundes.

Die zweite Strophe wiederholt zunächst die erste Hälfte des Oktotons. Bei dem ersten harmonischen Ereignis dieser Strophe (am Anfang von Takt 14) handelt es sich exakt um das erste Teil-Tetraton, diesmal zusammengefasst zu einem einzigen Akkord. Die Bewegung in den Takten 14 und 15 nach diesem Akkord könnte man vereinfacht als lineares Ausschreiten dieses Akkordes betrachten. In den Kadenz-Takten 16-18 erscheinen die vermittelnden Quinten fis-cis und e- $h$ (sie gehören nicht zum Hintergrund).

Kaum dass in der dritten Strophe die linke Hand einsetzt, erklingt die dritte Quinte cis-gis (um des Übergangs willen erscheint der obere Ton der Quinte erst auf dem dritten Viertel). Die vierte Quinte dis-ais erscheint auf dem Höhepunkt der Komposition (T. 24 ff.), der eben auch strukturell ein Höhepunkt ist, weil er das hintergründige Oktoton vollendet. Die Quinte ais-eis in den Takten 24 und 25 stellt (analog zur Quinte fis-cis in Takt 16) eine mittelgründige Erweiterung dar.

Der Hintergrund in Debussys Klavierstück The little Shepherd wird also durch diejenigen Quinten artikuliert, die das Klanggeschehen an exponierten Stellen grundieren. Die erwähnte obligate Lage ist die Lage der hintergründigen Quinten. Dass sie im Bereich der kleinen und eingestrichenen Oktave angesiedelt ist, lässt sich an den zentralen Stellen (T. 7, 14 und 21) unmittelbar erkennen. Einige tiefere Quinten (in den Kadenzen T. 9-11 und 16-18) kann man - aus Gründen der Klangfülle in den Kadenzen - als stiefergelegt betrachten (bei der tiefen Quinte $A_{1}-A$ in Takt 10 handelt es sich ohnehin um eine Wiederholung der obligaten Quinte a-e $e^{1}$ von Takt 7). Der Hinweis auf eine obligate Lage kann zwei Details klären:

1. Geht man von der Lage in Beispiel 16 aus, dann wäre die hintergründige Quinte des Dis-Dur-Akkordes in den Takten 24-26 diejenige der rechten Hand, während diejenige der linken wiederum der Klangverstärkung in der Kadenz dient. Die führende Rolle der höheren Quinte aber kommt in dem nachschlagenden Ton dis ${ }^{1}$ in Takt 26 zum Ausdruck. Die Aufmerksamkeit, die der Nachschlag erregt, gilt dem Ton selbst, aber auch seiner Funktion für den Übergang vom Höhepunkt zur (unvollständigen) Wiederholung der ersten Strophe: Die Terz $d^{1}-f^{1}$ der linken Hand schließt an $\operatorname{dis}^{1}$ an (durchaus im Sinne einer vordergründigen Stimme). ${ }^{25}$

2. Die Wiederholung der ersten Strophe (von Takt 27 an) setzt bei Takt 7 (und nicht etwa bei Takt 1 oder 5) ein, d. h. mit dem Erscheinen der ersten hintergründigen Quinte. Diese wiederum kann durch die Lagengleichheit auf die Quinte dis-ais zuvor bezogen werden.

Die Heptatone des Mittelgrundes

Die hintergründigen Quinten des Oktotons werden in den einzelnen Strophen bzw. Strophenabschnitten zu Heptatonen ausgebaut. Ähnlich wie beim hintergründigen Oktoton

25 Die Annahme, dass die vordergründige Stimmführung in Tonfeldkompositionen nicht zu den Konstituenten des musikalischen Zusammenhangs gehört, schließt umgekehrt nicht aus, dass Stimmführungsereignisse gelegentlich als Mittel dienen können, Tonfeldbeziehungen zu verdeutlichen. 
bilden auch hier die ersten beiden Strophen eine übergeordnete Einheit, die der dritten Strophe gegenüber steht.

So erscheint in der ersten Strophe das Heptaton $d$ bis gis, in der zweiten das quinthöhere Heptaton a bis dis. In der Summe bilden sie ein abstraktes Oktoton $d$ bis dis (das nirgendwo als solches erscheint). Die strukturellen Verhältnisse der Strophen 1 zu 2 finden sich um vier Quinten aufwärts versetzt in der dritten Strophe wieder: Sie enthält von Takt 21 (Mitte) an ein Heptaton fis bis his (auf den komplizierten Übergang wird später eingegangen). Mit Einsetzen der Schlussakkorde in Takt 24 wechselt der Tonvorrat in das quinthöhere Heptaton cis bis fisis. ${ }^{26}$
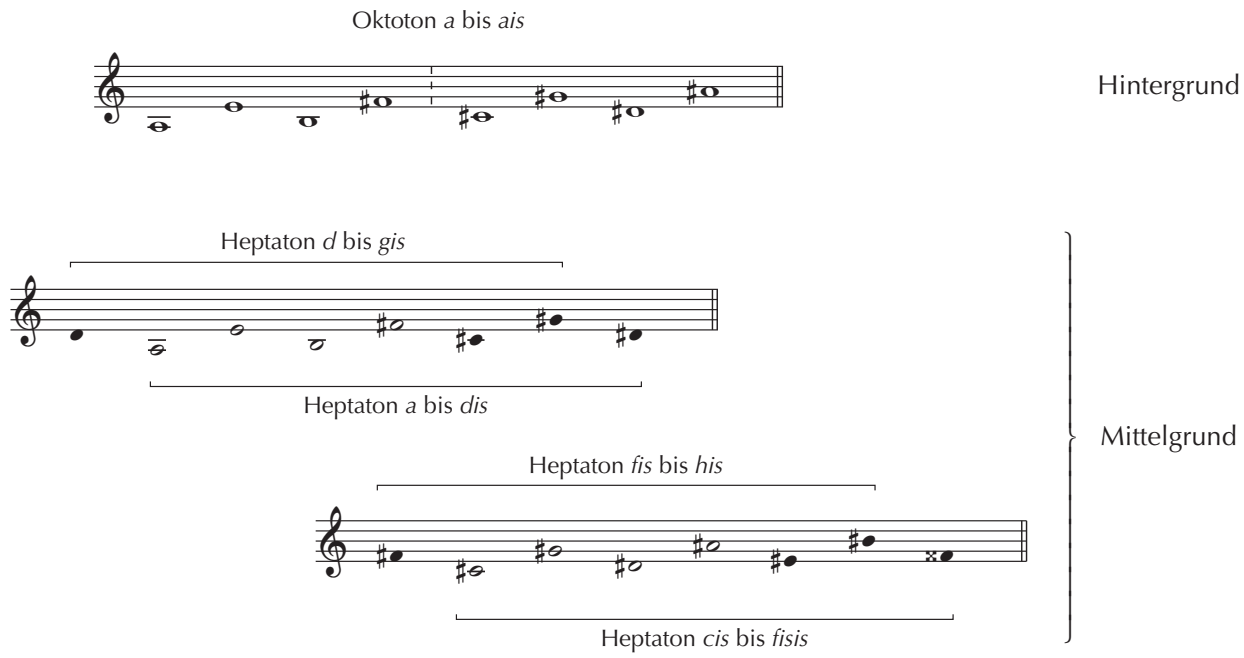

Mittelgrund

Beispiel 17: Claude Debussy, The little Shepherd (Mittelgrund)

Man beachte einige Analogien und Symmetrien:

- Die beiden mittelgründigen Teil-Oktotone, die ein gemeinsames Tetraton besitzen, stehen in jeweils derselben Position zu sihrem ‘ hintergründigen Teil-Tetraton.

- Die Heptatone in den Strophen 1 und 2 werden unvollständig exponiert und hernach ergänzt. Immer fehlt zunächst der Ton a, der Grundton der Komposition, und immer tritt er zunächst als Basston hinzu (bevor er in der Melodie erscheint). ${ }^{27}$ In der dritten

26 Von der Schichtenanalyse her gesehen, handelt es sich bei den Schlussklängen in den Takten 24-26 nur vordergründig um Dreiklänge mit Nonenvorhalt. Von ihrer Herkunft aus dem Hintergrund her sind die Klänge vielmehr als zwei Tritone zu interpretieren, denen eine Terz hinzugefügt wurde: aiseis-his + cis und dis-ais-eis + fisis. Diese Betrachtung hindert nicht daran, die Klänge in den Takten 24-26 als ais-Moll- und Dis-Dur-Dreiklang wahrzunehmen, aber sie regt an, in den Tönen his und eis Bestandteile des jeweiligen Klangs zu hören und nicht sharmoniefremde` Töne.

27 Das Fehlen des Tons a hat für das Heptaton a bis dis andere Auswirkungen als für das Heptaton $d$ bis gis. Im Heptaton a bis dis bildet a einen ıstrukturellen Ecktonı, sein Fehlen hinterlässt ein lückenloses Hexaton e bis dis. Heptaton $d$ bis gis hingegen bleibt auch ohne den Ton a ein Heptaton, nur 
Strophe erscheint Heptaton fis bis his immer vollständig und Heptaton cis bis fisis immer unvollständig (es fehlt der Ton gis).

- Alle vollständigen Heptatone werden je einmal in der Oberstimme als Skala vorgeführt. Die Position dieser Skalen unmittelbar vor den Kadenzen gibt ihnen etwas Zusammenfassendes: Heptaton $d$ bis gis erscheint abwärtsgerichtet in den Takten 8/9, Heptaton a bis gis ebenfalls abwärts in Takten 15 (4. Viertel) bis 16 (an beiden Stellen erscheint der bislang fehlende Ton $a^{1}$ zum ersten Mal in der Oberstimme) und Heptaton fis bis his schließlich - in Aufwärtsrichtung - in den Takten 22/23 (der Zielton der Melodie ais ist in der Oberstimme vor den Takten 23-26 noch nie erschienen).

\begin{tabular}{|c|c|c|c|c|c|c|c|c|c|c|c|}
\hline \multirow{2}{*}{$\begin{array}{l}\text { Strophe } \\
\text { Teile }\end{array}$} & \multicolumn{3}{|l|}{1} & \multicolumn{3}{|l|}{2} & \multicolumn{3}{|l|}{3} & \multicolumn{2}{|c|}{1 verkürzt } \\
\hline & $\mathrm{a}$ & b & C & $\mathrm{a}$ & $b$ & C & $\mathrm{a}$ & $b$ & C & b & C \\
\hline \multirow{2}{*}{$\begin{array}{l}\text { Tonfelder } \\
\text { (auf } \\
\text { Quinten } \\
\text { basis) }\end{array}$} & $\begin{array}{l}\text { Heptaton } \\
d \text {-gis } \\
\text { ohne a }\end{array}$ & & $\begin{array}{l}\text { Heptaton } \\
d \text {-gis }\end{array}$ & $\begin{array}{l}\text { Heptaton } \\
\text { a-dis } \\
\text { ohne a }\end{array}$ & \multicolumn{2}{|c|}{$\begin{array}{l}\text { Heptaton } \\
\text { a-dis }\end{array}$} & & $\begin{array}{l}\text { Heptaton } \\
\text { fis-his }\end{array}$ & $\begin{array}{l}\text { Heptaton } \\
\text { cis-fisis } \\
\text { ohne gis }\end{array}$ & & $\begin{array}{l}\text { Heptaton } \\
d \text {-gis }\end{array}$ \\
\hline & \multicolumn{6}{|c|}{ Oktoton $d$-dis } & \multicolumn{3}{|c|}{ Oktoton fis-fisis } & \multicolumn{2}{|c|}{ [Schluss] } \\
\hline Takte & $1-4$ & $5-8$ & $9-11$ & $12-13$ & $14-15$ & $16-18$ & $19-20$ & $21-23$ & $24-26$ & $27-28$ & $29-31$ \\
\hline
\end{tabular}

Abb. 2: Claude Debussy, The little Shepherd (Übersicht über die mittelgründigen Tonfelder)

Das Auskomponieren des hintergründigen Oktotons durch mittelgründige HeptatonPaare bringt die zwölf Töne der chromatischen Skala ins Spiel. Vereinfacht gesagt, durchläuft die Komposition - an den durch Quintenreihen bestimmten Takten - die zwölf Töne in etwa dieser Reihenfolge von $d$ bis fisis. Der Anstieg in Quinten ist für den Hörer fasslich. Jeder neue `quinthöhere` Ton bringt den sstammtongleichen` am unteren Ende zum Verschwinden. So ıgiltı der tiefste Ton der zwölftönigen Quintenreihe $d$ während der ersten Strophe. Sobald in der zweiten Strophe dis erscheint, ist $d$ verschwunden. Die Töne ais und eis ersetzen von der zweiten Hälfte in Takt 21 an nachhaltig die Töne a und e (auf die komplexen Verhältnisse der Takte 19 bis 21 Mitte wird gesondert eingegangen), his in Takt 22 verdrängt $h$, und fisis löst in Takt 24 fis ab.

Innerhalb der von Quintenreihen geprägten Takte gibt es keinen Ton $g$ und keinen Ton cisis. Die zwölf Töne bilden nicht einen Zirkel, sondern hinterlassen eine sstrukturelle Wolfsquinte fisis- $d$, die uns Debussy beim Übergang der Formabschnitte in den Takten 26/27 sinnlich vorführt (s. u.).

eben ein unvollständiges. Der Unterschied hat Folgen für die Klangwirkung; denn das signifikante Intervall des Heptatons (die übermäßige Quarte) prägt trotz fehlendem a den Klangcharakter des Beginns der Komposition (T. 1: gis-d). Dass hingegen die Melodie in den Takten 12/13 runder und ausgewogener klingt, hängt unter anderem damit zusammen, dass mit dem Auslassen des 'Ecktons` a dem (vorläufig unvollständigen) Heptaton die übermäßige Quarte fehlt. 


\section{Eingesprengte Tonfelder}

Vom Heptaton zur Funktion und zurück

Das erste Tonfeld, das nicht auf einer Quintenreihe basiert, ist die Funktion e/g/b/cis in Takt 5. Über die Ähnlichkeit zum vorangehenden Heptaton - über die Identität des oberen und die Halbtonversetzung des unteren Tetrachords - wurde bereits berichtet. Hier soll von den konkreten Übergängen die Rede sein.

Das obere Tetrachord e- $d$-cis- $h$, das beiden Tonfeldern gemeinsam ist, findet sich als gemeinsame Struktur der Oberstimmen sowohl in Takt 1 (5. bis 7. Achtel) als auch in Takt 5 (2. Viertel). Hinsichtlich der unteren Tetrachorde wird dasjenige des Heptatons, dessen Töne bekanntlich einen Halbtonschritt höher liegen als diejenigen der Funktion, in unmissverständlicher Weise in das Tetrachord der Funktion überführt. Die Tonfolge der Takte 2-4 kann als Austausch der höheren Töne $f i s^{2}$ und gis ${ }^{2}$ gegen die tieferen $f^{2}$ und $g^{2}$ interpretiert werden.

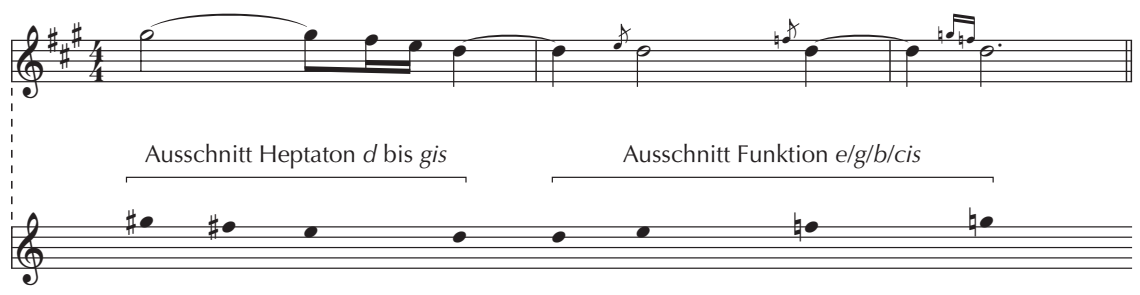

Beispiel 18: Claude Debussy, The little Shepherd, T. 2 ff. (Notentext und Analyse)

Der Weg von der Funktion zurück zur Quintenreihe geschieht im Wesentlichen in Takt 8. ${ }^{28}$ Dort wird der Ton $f$ (notiert als eis) zurück auf die Position fis hochgehoben. (Man beachte, wie - verglichen mit traditionellen Akkordfolgen - seltsam unbestimmt die Übergangs->Akkordfolge $h / d / f$ - h-Moll klingt). Anschließend füllt die Oberstimme den Weg zwischen den Tönen $h$ und gis/a, der seit Takt 5 offen gelassen worden war, mit dem Ton a. Damit ist der Ton unterhalb von a eindeutig als gis bestimmt (innerhalb der Funktion hatte Debussy den Tonort als as notiert).

Die Komplexität der dritten Strophe

Der Beginn der dritten Strophe ist komplex, er muss den Übergang von der ersten zur zweiten Hälfte des hintergründigen Oktotons zurücklegen, genauer: von der hintergründigen Quinte $h$-fis zur Quinte cis-gis. Mittelgründig gehören die Quinten je einem eigenen Heptaton an. Den Übergang aber vermittelt - sozusagen auf einer nächsten Schicht - das harmonische Oktoton a bis ais, das beide Quinten als zentrale Bestandteile enthält (nebenbei spiegelt das lokale harmonische Oktoton a bis ais das hintergründige Oktoton a bis ais wider). Allerdings ändern sich die Verhältnisse im Verlauf der Takte 19-21

28 Der eingeschobene H-Dur-Akkord in Takt 6 dient der Schlussbildung, aber - trotz der Töne dis und fis - noch nicht der Rückverwandlung der Funktion in das Heptaton. 
derart schnell, dass es nicht genügt, allein von einem Oktoton zu sprechen. Anders als das hintergründige Oktoton, dessen Quinten zu mehreren mittelgründigen Heptatonen erweitert werden, erscheint das Oktoton in diversen Teilmengen, die jeweils bestimmte Tonfelder andeuten.

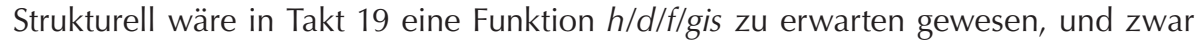
aus Gründen der Analogie: Wie auf das Heptaton $d$ bis gis in Takt 5 die Funktion e/g/b/ cis folgte, sollte auf das quinthöhere Heptaton die quinthöhere Funktion folgen. Tatsächlich erscheinen in den Takten 19/20 sechs Töne, die Teil dieser Funktion sein könnten. ${ }^{29}$ Es fällt jedoch auf, dass die 'Lücke` dieses Mal eindeutig als übermäßige Sekunde und nicht als kleine Terz wahrgenommen wird (der unheilvolle Klang dieser Stelle rührt unter anderem daher). Dieser Umstand legt nahe, die Takte 19/20 als Ausschnitt einer sharmonischen` Quintenreihe (Hexa-, Hepta- oder Oktoton) zu deuten.

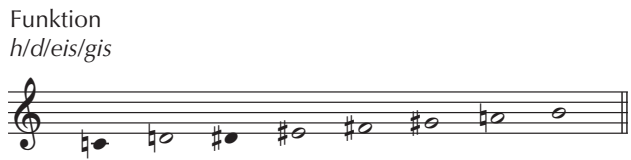

T. $19-20$ sharmonisches Oktoton< a bis ais

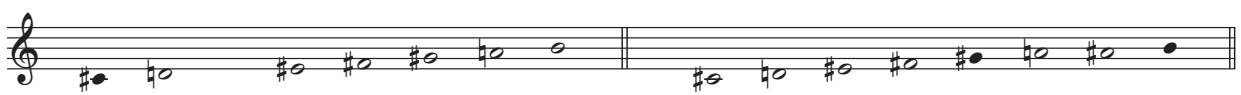

, harmonisches Heptaton a bis gis
T. 20-21 (Mitte)

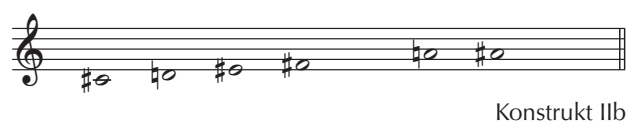

Beispiel 19: Claude Debussy, The little Shepherd, T. $19 \mathrm{ff}$. (beteiligte Tonfelder)

Geht man von einem harmonischen Heptaton aus, dann erfasst man nicht nur alle Töne der Takte 19/20 (inklusive die Qualität der übermäßigen Sekunde), sondern auch die hintergründige Quinte $\operatorname{cis}^{1}$-gis ${ }^{1}$ sowie - durch Erweiterung auf ein Oktoton - den Ton ais zu Beginn von Takt 20. Allerdings entspricht der Ausdruck von Einheitlichkeit, den die Interpretation durch ein einziges Tonfeld impliziert, nicht dem Klangeindruck der Takte. Der Übergang der Takte 20/21 ist klanglich durch eine auffallende Schärfe geprägt, die zuvor nicht bestanden hat und vom Hinzutreten der Töne cis und ais herrührt. Zu dieser Schärfe würde wiederum ein Konstrukt passen, und in der Tat lässt sich am Übergang der Takte 20/21 das Konstrukt IIb ausmachen - artikuliert durch zwei symmetrische Dreitongruppen. (Die Vollendung des Konstrukts ist an der sfalschen Akkord-Wirkung des vermeintlichen ais-Moll-Dreiklangs zu hören; man vergleiche diesen Akkord mit dem ais-Moll-Akkord in Takt 24.)

29 Melodisch beginnen die Takte 19/20 als Synthese aus erster und zweiter Strophe. Wie in der ersten finden sich die starke Exposition der übermäßigen Quarte $d$-gis und die Besetzung der hohen Lage $d^{2}$ bis $h^{2}$. Mit der zweiten Strophe teilt die dritte die melodisch-rhythmische Kontur sowie die >Lücke` zwischen dem untersten und dem zweituntersten Ton. 
Mit anderen Worten: Die Pointe der Takte 19-21 besteht im fließenden Übergang zwischen mehreren, einander ähnelnden Tonfeldern, die unter dem gemeinsamen Dach eines harmonischen Oktotons stehen. Jedes Tonfeld wird angedeutet, aber nicht festgehalten. So beginnt die Melodie als Schnittmenge aus Funktion und harmonischem Heptaton. Es fehlen exakt diejenigen Töne, die das Material auf ein bestimmtes Tonfeld hin festlegen würden (cis für das harmonische Heptaton, $c$ und dis für die Funktion). Für die Funktion spricht die Erwartung, für das harmonische Heptaton der spezifische Klangcharakter der `Lückeı. Am Ende von Takt 20 reduziert Debussy die Melodie auf die Töne um die >Lückes: $d$-eis-fis bilden ein shalbes`Konstrukt Ilb, das zu Beginn von Takt 21 um die zweite Hälfte cis-ais-a ergänzt wird. Alle Tonfelder bzw. Tonfeld-Ausschnitte können wiederum als Ausschnitte eines umfassenden harmonischen Oktotons verstanden werden (bei dem es sich mehr um die abstrakte Summe der einzelnen srealen um ein erklingendes Phänomen zu handeln scheint), das den Übergang zwischen den hintergründigen Quinten h-fis und cis-gis artikuliert.

\section{Takt 7}

Die Töne in Takt 7 passen auf den ersten Blick in kein Tonfeld hinein. Eine erste plausible Erklärung für ihre Zusammenstellung wäre der Hinweis auf die Vermischung von hintergründigen und mittelgründigen Ereignissen: Die Quinte a-e in der linken Hand wurde bereits als erste Quinte des Hintergrundes interpretiert. Lässt man diese Töne weg (oder zumindest den Ton a), dann passen alle übrigen in jene Funktion e/g/b/cis, die seit Takt 5 das Geschehen im Mittelgrund bestimmt hat. Das scheint aber noch nicht alles zu sein.

Im Gegensatz zu Takt 5 wirkt der Klang am Beginn von Takt 7 auffallend geschärft. Der Eindruck von Schärfe wird durch die Abwechslung mit der ^leeren` Quinte a-e verstärkt. Obwohl der Akkord $d$-f-cis theoretisch als Ausschnitt der Funktion e/g/b/cis interpretiert werden könnte, spricht seine Schärfe eher für eine Deutung als Konstrukt. Für

T. 7

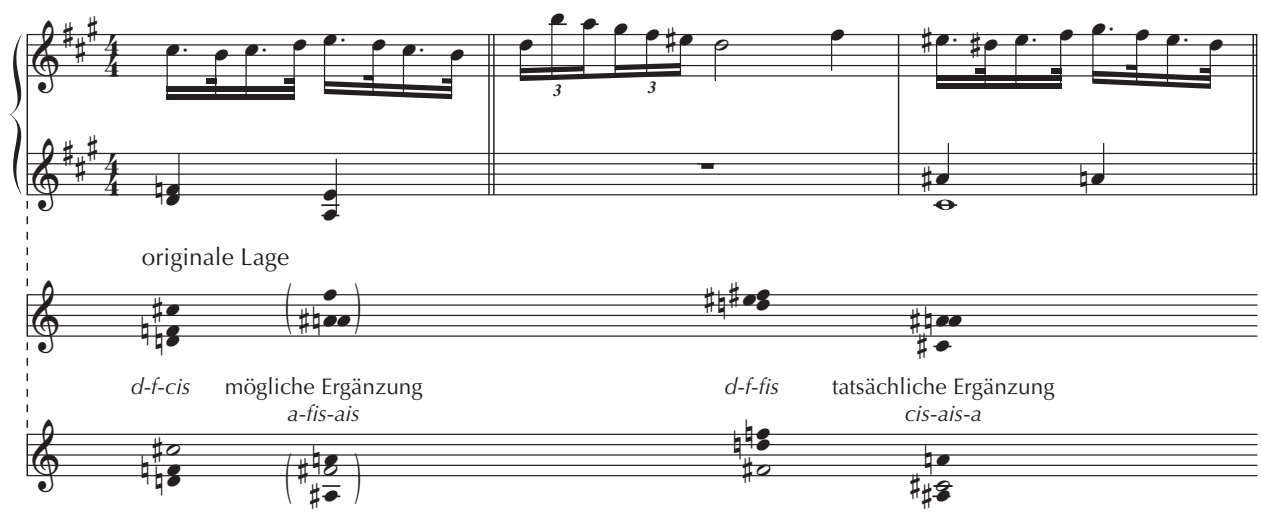

systematische Lagenanordnung

Beispiel 20: Claude Debussy, The little Shepherd, T. 7 und T. 20f. (Notentext und Analyse) 
ein Konstrukt wären die Töne ais, a und fis erforderlich, von denen zwei allerdings in unmittelbarer Nähe nicht auftauchen.

Tatsächlich bildet die dreitönige Konstellation $d$-f-cis eine Schnittmenge aus Konstrukt und Funktion. Durch die eine (ais-a-fis) oder andere Dreitongruppe (beispielsweise a-as-f) würde sie zu einem Konstrukt oder einer Funktion ergänzt. Diese Doppeldeutigkeit ist hier relevant. Obwohl sie theoretisch in die Umgebung der Funktion hineinpasst, verweist die Dreitongruppe durch ihre Klangeigenschaft auf das Konstrukt Ilb zu Beginn der dritten Strophe (auch hier ist es die Analogie der Klangeigenschaften, die die Takte 7 und 20/21 aufeinander beziehbar macht). Man könnte sagen: Die Dreitongruppe cis- $d-f$ kehrt in Takt 20 modifiziert als $d$-f (eis)-fis wieder und wird dort - wie bereits erwähnt - durch cis-ais-a ergänzt (die weißen und schwarzen Notenköpfe in der untersten Zeile von Beispiel 20 deuten an, dass sich die Ereignisse in Takt 7 und den Takten 19/20 vor allem durch die Position der Töne fis und cis in den Dreitongruppen unterscheiden). Das Konstrukt IIb in den Takten 20/21 bildet trotz der Verbindung zu Takt 7 kein hintergründiges Tonfeld.

\section{Der Schluss}

Das Wiederaufgreifen eines ersten (`tonikalen`) Formteils geschieht im 18. und frühen 19. Jahrhundert in der Regel, um den Prozess der Tonartdarstellung durch Herbeiführen einer Schlusstonika zu einem Ende zu führen. In einem auf Tonfeldern basierenden Stück wie Debussys The little Shepherd jedoch bedarf die Wiederholung der Takte 7-11 als Schlussteil einer veränderten Rechtfertigung. Wozu gibt es die Takte überhaupt, wenn doch die Darstellung des hintergründigen Oktotons und der mittelgründigen Heptatone auf dem Höhepunkt in Takt 24 abgeschlossen wurde?

Die Antwort liegt in dem Effekt, den der Rücksprung von Takt 26 auf Takt 7 auslöst. ${ }^{30}$ Wie bereits angedeutet, sind Quintenreihen Ausschnitte aus einer nach beiden Seiten offenen Kette von reinen Quinten. Sie kennen - im Gegensatz zu Funktionen und Konstrukten - keinen Zustand von Vollständigkeit. Wenn im Zusammenhang mit den Takten 24-26 von einer Vervollständigung die Rede war, dann unter zwei Gesichtspunkten: zum einen hinsichtlich der im Hintergrund und Mittelgrund 'gesetzten، Tonfelder, zum anderen hinsichtlich der Quintenreihe von $d$ bis fisis, die sich aus der Kombination der mittelgründigen Tonfelder ergibt und nicht eigentlich ein Tonfeld darstellt. Im letzten Fall gründet der Gedanke der Vollständigkeit nicht in einer Eigenschaft der Quintenreihe, sondern in der Auffassung, dass die zwölf Töne der chromatischen Skala (als pitch-classes betrachtet) eine Totalität bilden können. Theoretisch ist dieses Verhältnis nicht spannungslos. Ein Hintergrund aus pitch-classes gibt einen Begriff von Vollständigkeit, aber kennt keinen Unterschied zwischen fisis und g. Quintenreihen hingegen unterscheiden zwischen fisis und $g$, aber kennen keinen Zustand von Vollständigkeit. ${ }^{31}$

Die Pointe des Übergangs zwischen Takt 26 und 27 besteht darin, die vollzogene Vollendung der Zwölftönigkeit (trotz Quintenreihe) hörbar zu machen. Dies geschieht

30 Vgl. Haas i. V.

31 Der unmittelbare Abschluss-Effekt, der von den Dis-Dur-Akkorden in den Takten 24-26 ausgeht, rührt von der kadenziellen Konstellation her, nicht vom Erreichen des Tons fisis. 
dadurch, dass der Fortgang der steigenden Quintenreihe zum nächsten `dreizehnten Ton als Rückkehr zum Ausgangspunkt erscheint. Die Rückkehr wiederum teilt sich in dem Eindruck mit, dass das Geschehen nach dem Dis-Dur-Akkord um einen halben Ton zu tief fortsetzt. Ein Experiment kann diesen Gedanken erhellen.
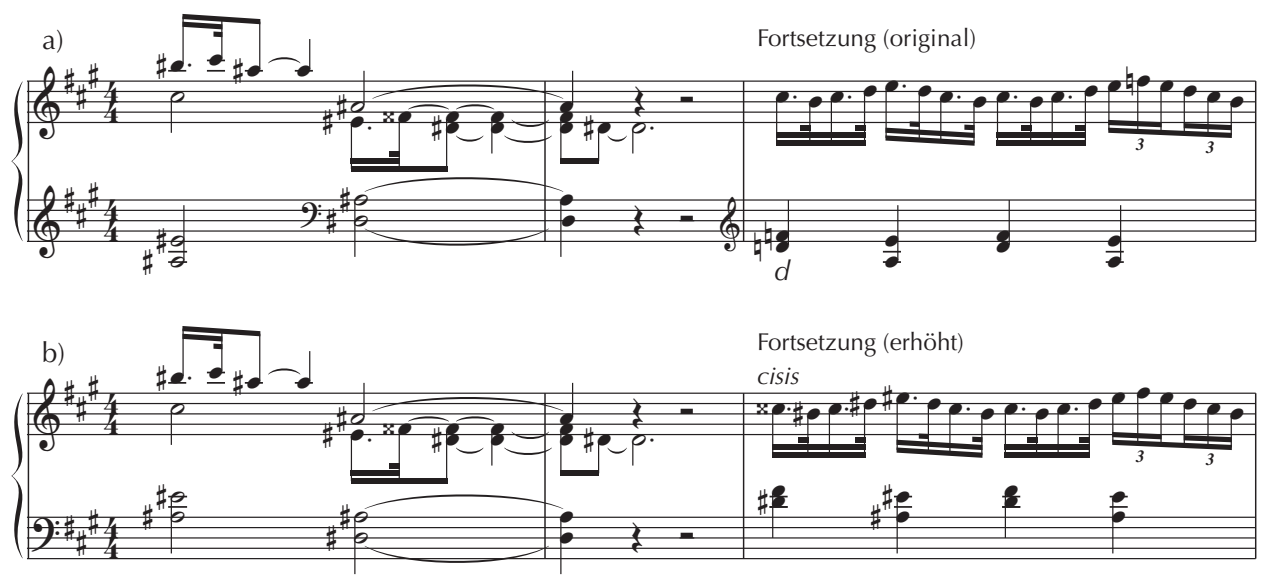

Beispiel 21: Claude Debussy, The little Shepherd, T. 25 ff. (Originaltext und Variante)

In der zweiten Version (Beispiel 21b) schließt Takt 27 bruchlos an das Geschehen von zuvor an. Der klanglichen Kontinuität entspricht die Tatsache, dass die Quintenreihe aufwärts fortgesetzt wird; denn der Anfangston der Melodie ist unmissverständlich als cisis bestimmt (wenn der Schlussakkord in Takt 26 Dis-Dur lautet und der tiefste Ton dis ${ }^{1}$ liegen bleibt, so muss die Septime darüber cisis ${ }^{2}$ lauten). Die originale Fassung jedoch lässt den Tonsatz nach der Zäsur in Takt 26 sabsackenı, und diesem Eindruck entspricht eine Fortsetzung mit dem Ton $d^{1}$ (dass es sich um $d$ handelt, wird nicht nur durch das wörtliche Wiederaufgreifen von Takt 7, sondern vor allem durch den bereits beschriebenen Übergang der Takte 26/27 deutlich, der uns $d$ als stiefergestimmtes` dis vorführt).

Mit anderen Worten: Takt 27 setzt den >Dis-Dur-Akkord von Takt 26 mit einem Klang fort, der den Tonort $d /$ cisis enthält. Dieser Tonort erscheint funktional jedoch nicht als Oberquinte zu fisis, sondern als tiefergestimmtes dis oder - sozusagen - als übermäßige Terz unter fisis (vgl. die erwähnte `Wolfsquinte`). Motivisch-thematisch suggeriert der Einsatz von $d$ zudem eine Rückkehr zum anfänglichen Geschehen der Komposition, das sich noch im Bereich der Quintenreihe von $d$ bis gis aufhielt. Somit ist das ^Absenken des Tonsatzes um einen Halbtonschritt nach Takt 27 unmittelbarer Ausdruck davon, dass die Fortsetzung der Quintenreihe wieder an den Anfang zurückführt.

\section{Stockhausen, Klavierstück III}

Alle bisherigen Erfahrungen mit der Tonfeld-Analyse ${ }^{32}$ lassen die Hypothese, dass Tonfelder ein Stück impliziten Wissens gebildet haben, unter anderem bei Brahms, Bruckner, 
Schönberg und Webern plausibel erscheinen. Gerade angesichts der Kompositionen von Schönberg und Webern um das Jahr 1909 kann man mit Hilfe der Tonfeld-Theorie sogar den sogenannten >Übergang zur Atonalitätı als Kontinuität statt als Systemwechsel begreifen, weil sie die kompositorischen Veränderungen als veränderte Inanspruchnahme der Tonfelder interpretiert und nicht als Preisgabe der straditionellen Tonalität. Kann es aber Tonfelder noch in seriellen Kompositionen von Stockhausen geben? Das hängt von zwei Voraussetzungen ab:

1. Zum einen müsste eine historische Kontinuität des Denkens in Tonfeldern über Schönberg und Webern hinaus glaubhaft gemacht werden. Ein Versuch in diese Richtung (der in diesem Beitrag nicht geleistet werden kann) würde selbstverständlich nicht von den Äußerungen der Komponisten, sondern von den Analysen ihrer Kompositionen ausgehen müssen. Vor allem zwölftontechnischen Werken wäre eine besondere Aufmerksamkeit zu schenken. ${ }^{33}$ Ist man der Überzeugung, dass in der Zwölftontechnik Weberns Tonfelder wirken, dann könnten Spuren des Denkens in Tonfeldern auch noch in den 50er Jahren bei Stockhausen zu finden sein, der partiell von Webern ${ }^{34}$ (und auch Messiaen, bei dem ein Denken in Tonfeldern offensichtlich ist) beeinflusst worden ist.

2. Zum anderen setzt die Annahme von Tonfeldern in Klavierstück III die Überzeugung voraus, dass die serielle Technik keine Determination des musikalischen Zusammenhangs darstellt, sondern ein Mittel zu dessen Realisierung: Der serielle Apparat kann für jede einzelne Komposition so einrichtet werden, dass er die vom Komponisten intendierten Klangergebnisse hervorbringt. ${ }^{35}$ Insbesondere die Abweichungen von den seriellen Vorgaben, die Christoph von Blumröder im dritten Klavierstück aufgezeigt hat, dürften aufschlussreich sein, weil Stockhausen bei seinen Eingriffen in den seriellen Apparat anderen als seriellen Zwecken gefolgt sein muss.

Für das dritte Klavierstück schlage ich folgende Interpretation vor: ${ }^{36}$

32 Vgl. hierzu Analysen zu Kompositionen von Bruckner, Schönberg und Webern bei Haas (2004, i. V.) und Polth (2007, 2009).

33 Bernhard Haas hat bereits den zweiten Satz der Variationen op. 27 von Anton Webern nach Tonfeldern analysiert (2004).

34 Pascal Decroupet hat gezeigt, dass der Einfluss Weberns auf Stockhausen geringer und auch chronologisch später anzusetzen ist, als gemeinhin angenommen wird.

35 Dass die Klangintentionen eines seriellen Komponisten von vornherein solche sein müssen, die sich durch einen seriellen Apparat realisieren lassen, stellt keinen Widerspruch zur obigen Aussage dar, wenn man von einem wechselseitigen Einfluss von Klangvorstellung und Kompositionstechnik ausgeht.

36 Die Interpretation wird in den folgenden Abschnitten kommentiert, das Ergebnis aber nicht beurteilt. Eine abschließende Beurteilung ist allein deswegen nicht möglich, weil es bislang nicht gelungen ist, für ein anderes der (Solo-)Klavierstücke Stockhausens vor 1970 eine konsistente Tonfeld-Analyse anzufertigen. Letzteres legt die Vermutung nahe, dass die eingangs formulierte Hypothese für diese Kompositionen nicht gilt (die Komposition Mantra für zwei Klaviere und Ringmodulator aus dem Jahre 1970 deutet vom Klang her allerdings wieder sehr stark auf Tonfelder hin). 


\section{1. Übersicht}

Das Klavierstück gliedert sich in drei Abschnitte, die drei komplexen Tonfeld-Sachverhalten entsprechen. Abschnitt 1 (T. 1-4) ist eine Art Exposition mit einem einzigen Tonfeld. Abschnitt 2 (T. 5-10) bildet einen kontrastierenden Mittelteil, der zwei weitere Tonfelder darstellt und miteinander verschränkt. Abschnitt 3 (T. 11-16; beginnend beim Ton c am Ende von Takt 10 - dem ersten c in dieser Komposition) stellt zu Beginn eine komplizierte Synthese der ersten beiden Abschnitte dar. Die übersichtlichsten Verhältnisse zeigt der zweite Abschnitt, mit dem die Erläuterung deswegen beginnen soll.
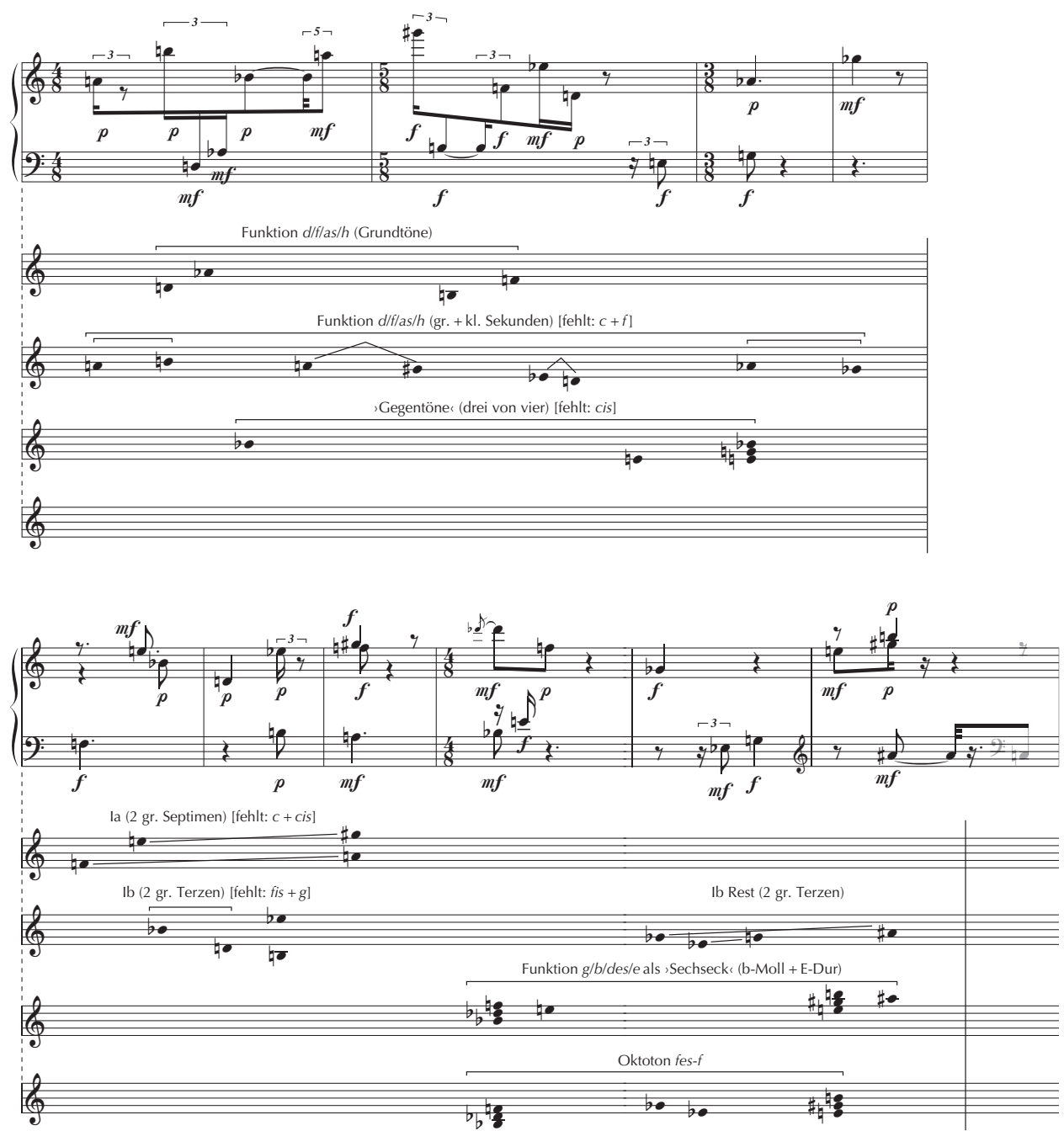

Beispiel 22: Karlheinz Stockhausen, Klavierstück III (Notentext und Analyse) 


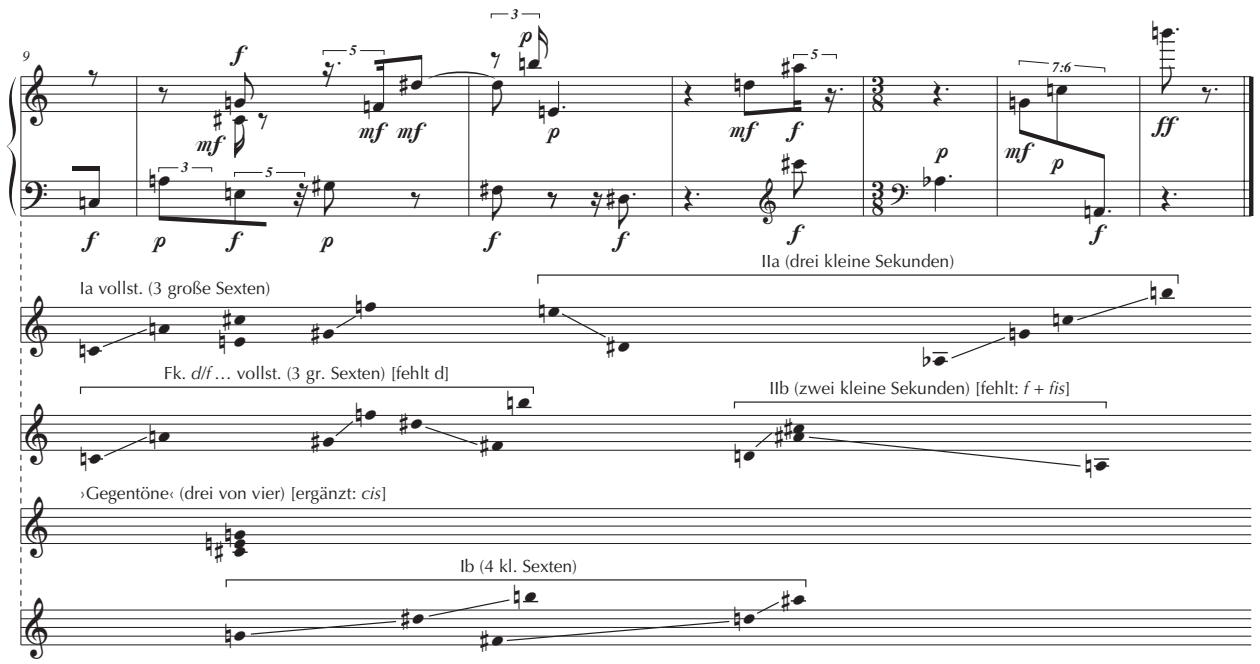

Beispiel 22 (Fortsetzung)

\section{Mittelteil}

Abschnitt 2 besteht aus zwei Unterabschnitten von $3+3$ Takten. Jeder Dreitakter ist auf eigene Weise gestaltet.

Der erste Dreitakter verschränkt die beiden Konstrukte la und Ib. Beide Konstrukte enthalten lediglich vier ${ }^{37}$ von sechs Tönen (sie werden später vervollständigt), und beide werden in Tonpaaren artikuliert, die in irgendeiner Weise mit großen Terzen zu tun haben. Konstrukt la umrahmt Konstrukt Ib. Die Töne von la besitzen die dynamischen Werte Forte und Mezzoforte (jeweils ein Ton Forte, einer Mezzoforte), diejenigen von Ib stehen ausschließlich im Piano. Die Töne der Tonpaare von la bilden - übereinander gelegt - jeweils eine große Septime, diejenigen von lb eine große Terz bzw. kleine Sexte (Intervallklasse 4). Die große Terz spielt in Konstrukt la insofern eine Rolle, als die jeweils oberen und unteren beiden Töne, die nacheinander erscheinen, eine große Terz voneinander entfernt sind. In jedem der beiden Konstrukte erklingt das erste Tonpaar simultan, das zweite sukzessiv.

Der zweite Dreitakter artikuliert die Funktion $\mathrm{g} / \mathrm{b} / \mathrm{des} / \mathrm{e}$, ähnlich wie die Konstrukte zuvor: unvollständig mit sechs von acht Tönen. Und ähnlich wie im Dreitakter zuvor umrahmt ein säußeres` Tonfeld, diesmal die Funktion, eine sinnere` Tonkonstellation. Bei den sumrahmten Tönen handelt es sich nicht um eine weitere Funktion, sondern um Töne, die das Konstrukt lb von zuvor vervollständigen. Beides - sowohl die Funktion als auch der >Rest` des Konstrukts lb - wird deutlich artikuliert. Die Funktion erscheint als `Sechseckı (`b-Molk und >E-Dur`), zusätzlich wird in jedem `Dreiklang` der `Grundton` des jeweils anderen `Dreiklangs` hineingefügt ( $e$ in `b-Molk und $b$ bzw. ais in >E-Dur`).

37 Der Ton $f$ in Konstrukt la erscheint doppelt. 


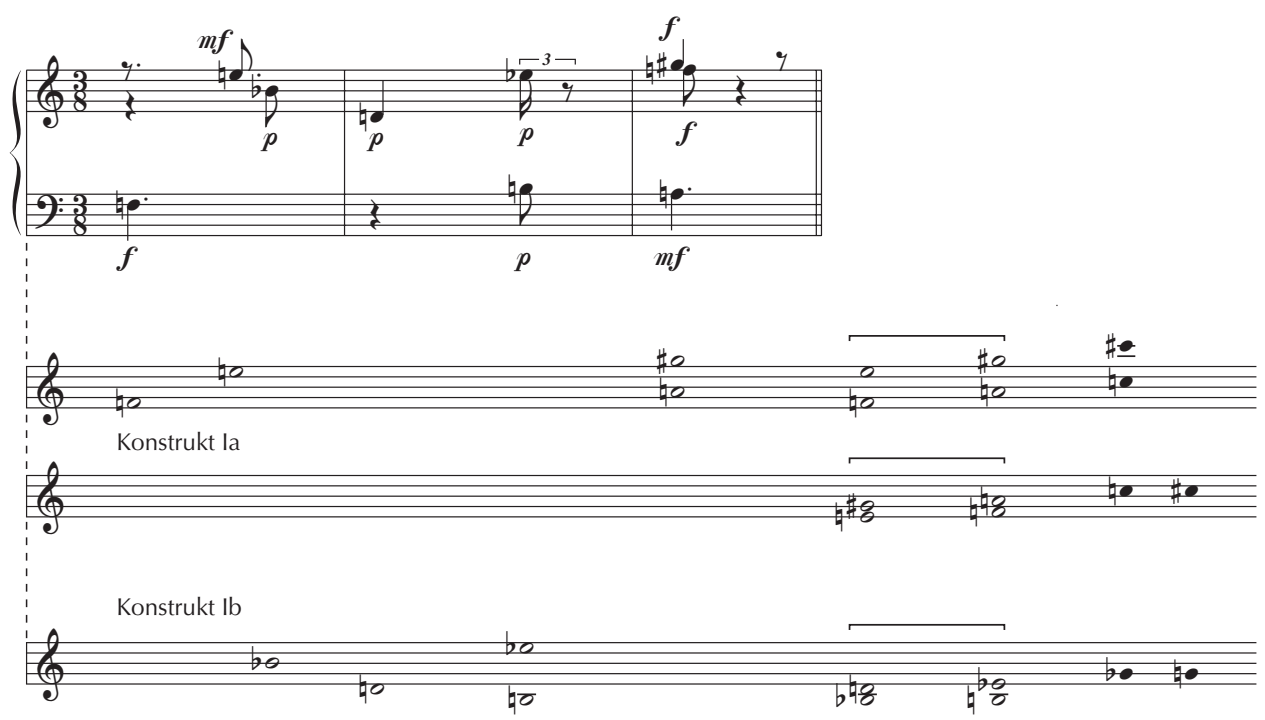

Beispiel 23: Karlheinz Stockhausen, Klavierstück III, T. 5 ff. (Notentext und Analyse)
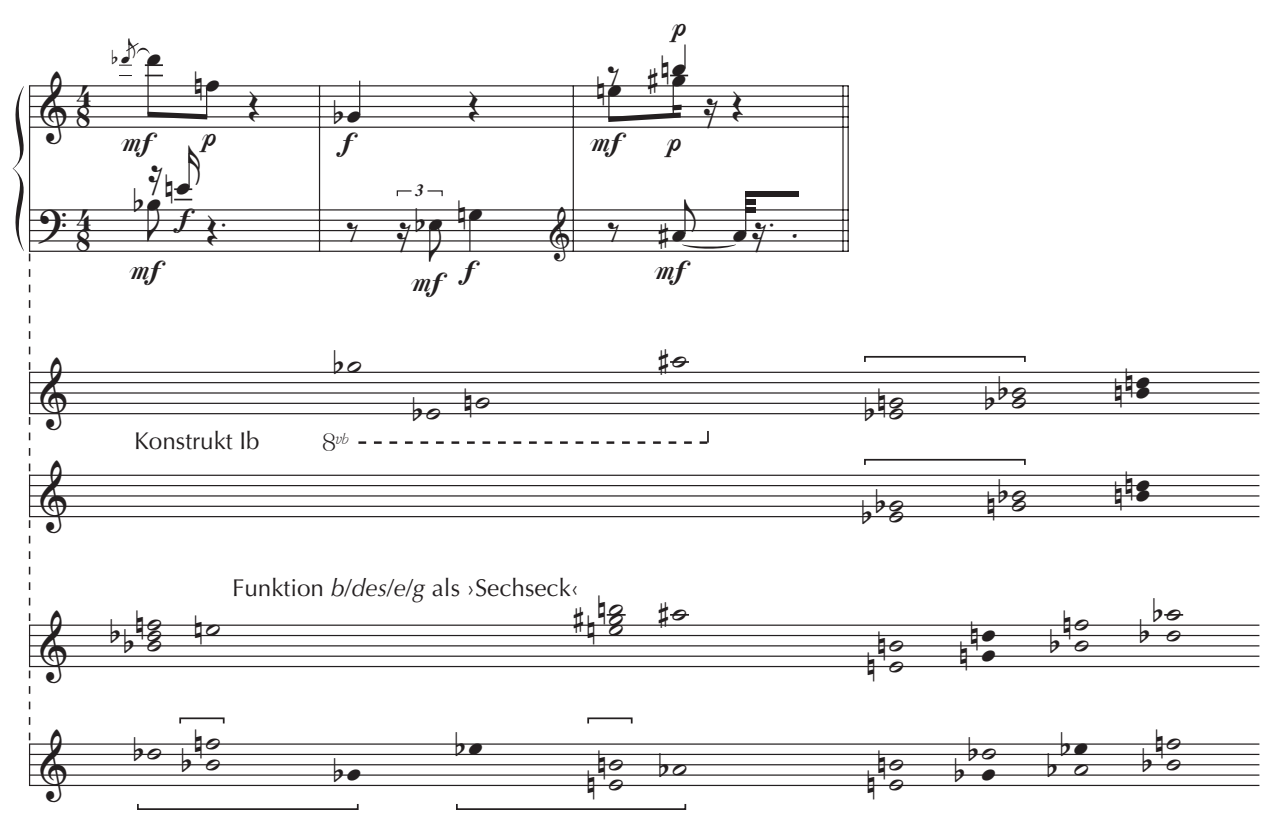

Oktoton fes bis $f$

Beispiel 24: Karlheinz Stockhausen, Klavierstück III, T. 8-10 (Notentext und Analyse) 
Die sDreiklänge ‘ erscheinen immer in zwei sukzessive Achtel zerlegt, wobei das erste jeweils im Mezzoforte, das zweite im Piano steht. Ein Sechseck kann durch jeweils zwei zusätzliche Töne zu zwei unterschiedlichen Tonfeldern ergänzt werden. Füge ich den Tönen $b$-des-f-e-gis- $h$ die Töne $g$ und $d$ hinzu, würde die beschriebene Funktion vervollständigt (diese Vervollständigung erscheint bei Stockhausen nicht). Eine Ergänzung durch die Töne ges und es macht aus dem Sechseck ein 〉Oktoton fes bis $f:$ fes $(=e)$-ces $(=h)$ ges-des-as(=gis)-es- $b$-f. Die Töne es und ges erscheinen an prominenter Stelle in Takt 9.

Wie bereits erwähnt, wird in Takt 9/10 das Konstrukt Ib ergänzt. Es erscheinen wiederum zwei Tonpaare, deren Töne - nimmt man jeweils die oberen und unteren beiden Töne zusammen - zwei große Terzen bilden: ges-b (bzw. ais) und es-g (der Ton ais gehört somit zwei Tonfeldern an). Nimmt man hingegen jeweils die ersten und letzten beiden Töne zusammen, ergeben sich zwei kleine Terzen: es-ges und $g$ - $b$. Wie immer man die vier Töne aufteilt: In jedem Paar erklingt ein Ton im Mezzoforte und einer im Forte, und die Töne fis bzw. ges und $g$, die in den Takten 5/6 fehlten, um das Konstrukt lb zu vervollständigen, erscheinen auf zwei Paare verteilt.

\section{Erster Teil}

Die ersten vier Takte lassen sich aus sich selbst heraus nicht so plausibel erklären wie die Takte 5 bis 10. Für eine begründete Interpretation muss die Analyse des dritten Abschnitts mitherangezogen werden. Dennoch seien die strukturellen Verhältnisse des ersten Teils zunächst thesenhaft genannt.

Der erste Teil artikuliert eine Funktion $d / f / a s / h$ (mit sieben von acht Tönen, es fehlt $c$ ) sowie drei `Gegentöne` (drei von vier Tönen, die in der Funktion nicht enthalten sind). Faktisch gibt es in den ersten vier Takten fünfzehn Anschläge des Klaviers mit insgesamt zehn Tonqualitäten (es fehlen insgesamt nur die Töne $c$ und cis). Dass sieben dieser zehn Töne ein achttöniges Tonfeld - dazu noch ein unvollständiges - bilden sollen, klingt für sich genommen noch nicht überzeugend, vor allem angesichts der Tatsache, dass sich aus zehn Tönen alle möglichen Tonfelder bilden lassen. Doch statistisch überwiegen die Grundtöne der Funktion: Der Grundton as erscheint dreimal, die Grundtöne $d$ und $h$ zweimal. Zweimal erscheint ebenfalls der Quintton a, die Töne $f$ (Grundton), es und ges (Quinttöne) gibt es nur einmal. Allerdings gibt es jeweils einmal auch die Töne e, $g$ und $b$, die nicht zur Funktion gehören. Immerhin ist die Funktion $d / f / a s / h$ die einzige (von drei möglichen), die sich aus den vorhandenen Tönen mit sieben Beteiligten und sämtlichen Grundtönen bilden lässt.

Was statistisch eher vage bleibt, erhärtet sich bei Betrachtung der Tongruppierungen. Die Grundtöne des Funktion $d, f$, as und $h$ bilden in den ersten acht Achteln (bis zur Zählzeit vier des zweiten Taktes) die tiefsten Töne. Zudem erscheinen sie - das scheint bestimmend für diese Komposition zu sein - paarweise geordnet: Zwei Tritoni ( $d$-as und $h-f$ ) heben sich von ihrer Umgebung deutlich ab, auch dynamisch bilden die zusammengehörigen Töne jeweils ein Paar. ${ }^{38}$ Die sfremden` Töne $e, g$ und $b$ lassen sich nicht

38 Laut Christoph von Blumröders Rekonstruktion der seriellen Strukturen hätte anstelle des Tons $d$ der Ton $B$ bzw. b erscheinen müssen $(1993,127)$. In diesem Fall hätte Stockhausen die Vorgaben 


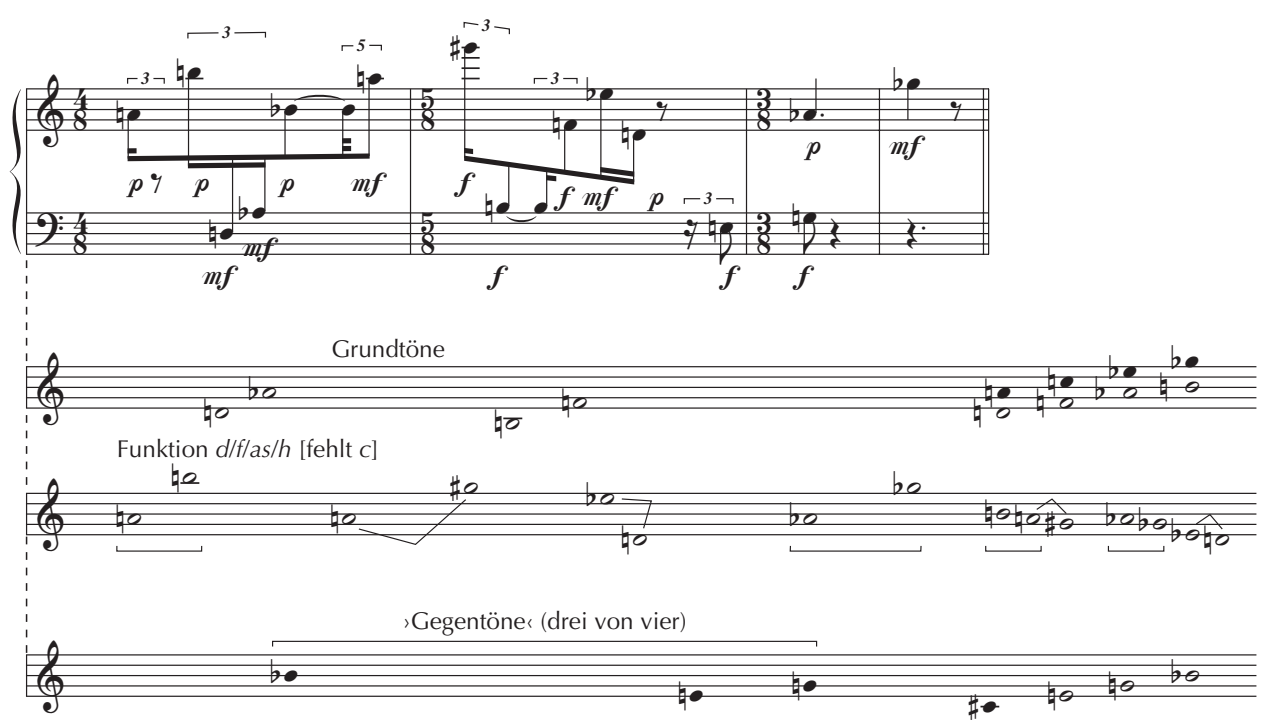

Beispiel 25: Karlheinz Stockhausen, Klavierstück III, T. 1-4 (Notentext und Analyse)

konsequent von den anderen unterscheiden. Zwar heben sich die Töne e und $g$ von der Septime as-ges durch die dynamischen Grade ab (die Dynamik lässt deutlich zwei verschiedene Schichten in linker und rechter Hand erkennen), aber damit wäre noch nicht der Ton $b$ erklärt, der inmitten der angeblichen Funktion auftaucht und von den übrigen Tönen nicht auffällig unterschieden ist. In der Tat kann zur Begründung dieser Interpretation hier nur ein Verweis auf Abschnitt 3 helfen.

\section{Schlussteil}

In Abschnitt 1 erscheint also - folgt man den bisherigen Ausführungen - die Funktion d/f/ as/h mit sieben von acht Tönen und zudem drei Töne des verbleibenden 'Septakkordes` e-g-b (cis fehlt). Exakt dieselbe Situation findet sich zu Beginn des dritten Abschnitts. Betrachtet man (von c in Takt 10 - letzter Ton - aus gerechnet) die ersten zehn Anschläge des Abschnitts, so finden sich sieben Töne der Funktion $d / f / a s / h$ und drei Töne des verbleibenden Septakkordes. Diesmal aber sind die Unterschiede zwischen den Tonfeldern klar artikuliert: Die Töne der Funktion erscheinen als große Sexten (mit Ausnahme des Tons $h$ ), die sfremden Töne als Akkord. In der Funktion fehlt an dieser Stelle der Ton $d$ und im Septakkord der Ton $b .{ }^{39}$ Diese deutliche Analogie zu den Takten 1 bis 4 lässt die im letzten Kapitel angebotene Deutung plausibel erscheinen.

durchbrochen und sich bei seiner Entscheidung von anderen als von seriellen Gesichtspunkten leiten lassen. Ein solcher Gesichtspunkt könnte die Struktur des Tonfeldes `Funktion ‘ gewesen sein.

39 Ein Ton $d^{2}$, der die Funktion zur Vollständigkeit ergänzen könnte (und der sogar eine große Sexte zum Ton $h^{2}$ bildet), findet sich in Takt 13 (überdies ergäbe sich durch seine Hinzunahme eine schöne 


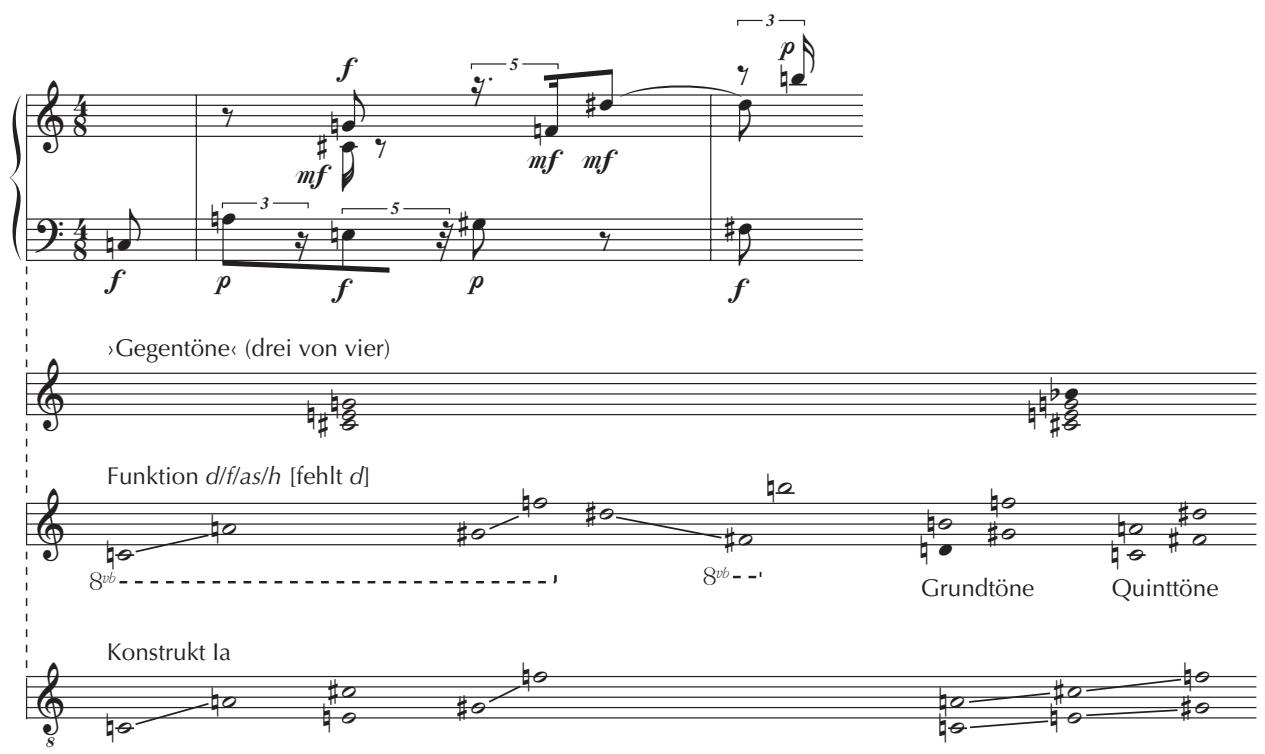

Beispiel 26: KarlheinzStockhausen, KlavierstückIII, Beginn des Schlussteils (Notentextund Analyse)

Die Pointe zu Beginn des dritten Teils ist jedoch die Synthese aus Funktion und Konstrukt la; denn sechs der Töne von Takt 10 (letzter Ton) an artikulieren neben der Funktion auch das Konstrukt la, jenes Konstrukt des Mittelteils also, das bislang unvollständig geblieben ist. Auch hier sind es die großen Sexten, aus denen sich das Konstrukt zusammensetzt. Anders als in der Funktion muss hier die Sexte e-cis des Akkordes mitgezählt werden: $c-a$, e-cis, gis-f. Wegen der Regelmäßigkeit der Lagenverteilung erscheint auch eine Darstellung des Konstrukts als zwei übermäßige Dreiklänge sinnvoll: c-e-gis $+a-c i s^{1}-f^{1}$.

Gemessen an der Komplexität der Komposition ist das Ergebnis der Analyse überraschend deutlich. Der Verdacht, dass es sich um einen Zufall handeln könnte, verflüchtigt sich jedoch ein wenig, wenn man sieht, dass auch ein Komponist wie Henry Pousseur zu Beginn seines Impromptus (1954) Konstrukte aneinander reiht, ohne hiervon in seinem Kommentar ${ }^{40}$ das Geringste zu erwähnen (Beispiel 27).

Symmetrie zwischen den beiden aufsteigenden Sexten c-a/gis- $f^{1}$ und den beiden fallenden dis $^{2}-$ fis $\left./ h^{2}-d^{2}\right)$. Ich zögere jedoch, diesen Ton hinzuzunehmen, da ich - zumindest im Hinblick auf die Funktion $d / f / a s / h$ - keine Kontinuität zum Anfang des dritten Formteils erkennen kann (wohl aber besteht eine Kontinuität durch das Konstrukt Ib, Takte 11-13, s. Beispiel 22).

40 Pousseur 1957. 


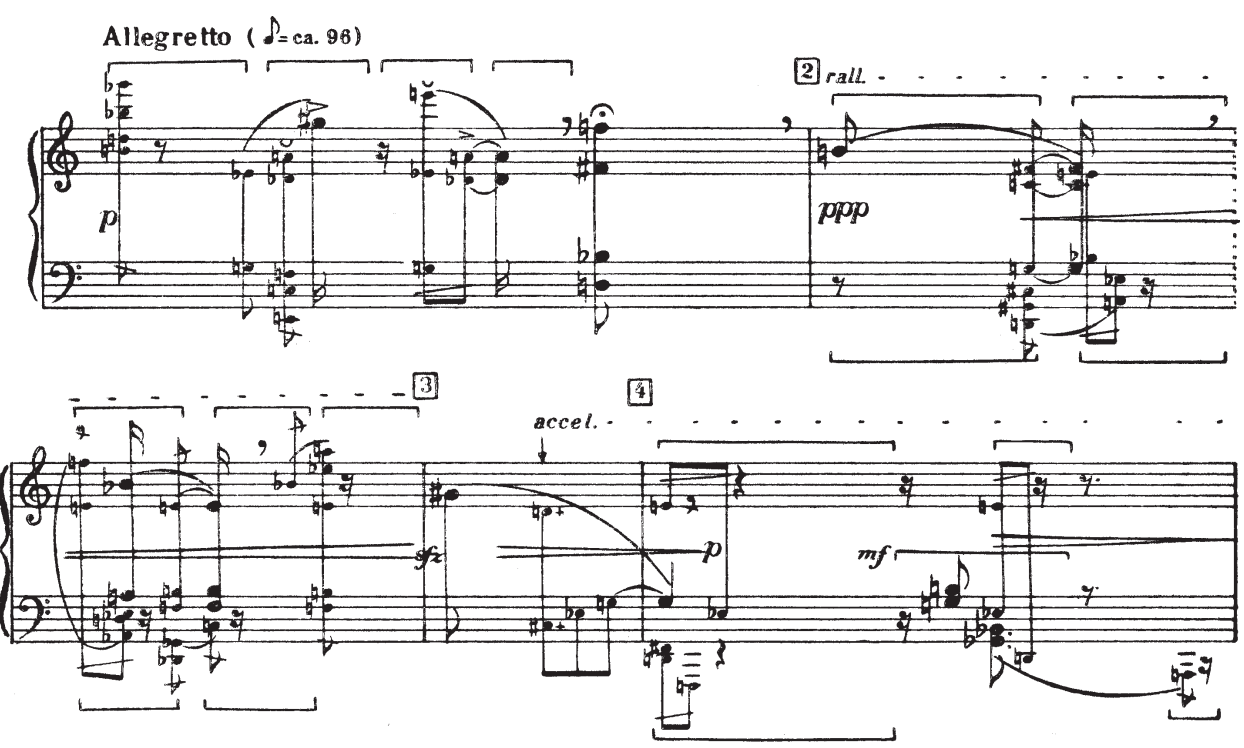

Beispiel 27a: Henry Pousseur, Impromptu, T. 1-4

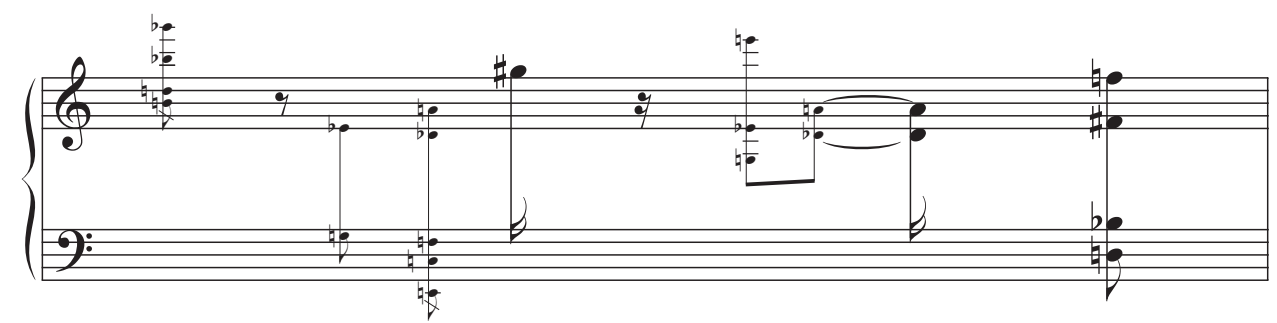

Ib

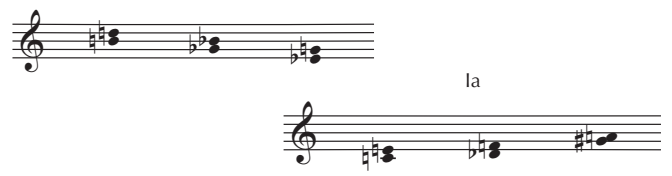

Beispiel 27b: Henry Pousseur, Impromptu, T. 1: Analyse 


\section{Literatur}

Blumröder, Christoph von (1993), Die Grundlegung der Musik Karlheinz Stockhausens (= Beihefte zum Archiv für Musikwissenschaft, Bd. 23, hg. von Hans Heinrich Eggebrecht), Stuttgart: Franz Steiner.

Decroupet, Pascal (1999), »First sketches of reality: Fragmente zu Stockhausen Klavierstück VI««, in: Die Anfänge der seriellen Musik: Eine Publikation des Instituts für Neue Musik der Hochschule der Künste Berlin, hg. von Orm Finnendahl, Hofheim: Wolke, 97-133. http://www.musikbibliographie.de/SET=2/TTL=25/MAT=/NOMAT=T/ CLK? IKT=12\&TRM=001862774

Haas, Bernhard (2004), Die neue Tonalität von Schubert bis Webern. Hören und Analysieren nach Albert Simon, Wilhelmshaven: Noetzel.

(i. V.), »Analytische Fragmente zum ersten Satz von Bruckners VI. Symphonie», in: Brahms und Bruckner, Musiktheoretisches Symposion Linz 2008, hg. von Christoph Hust.

Polth, Michael (2007a), „Zum Verhältnis zwischen Satztechnik und musikalischem Zusammenhang: Bemerkungen zu einer Sequenz in Bruckners 6. Symphonie«, in: `Vom Erkennen des Erkannten. Musikalische Analyse und Editionsphilologie. Festschrift für Christian Martin Schmidt, hg. von Thomas Ahrend, Heinz von Loesch und Frederike Wißmann, Wiesbaden u. a.: Breitkopf \& Härtel, 335-344.

— (2007b), "Satztechnische Modelle und moderne Tonalität. Zu einem Archaismus in Bruckners d-Moll-Messe», in: Bruckner-Tag Mannheim 2006: Anton Bruckner - Die geistliche Musik (= Bruckner-Vorträge), hg. von Rainer Boss, Wien: Musikwissenschaftlicher Verlag, 47-64.

(2009), »Atonalität und musikalischer Zusammenhang in Weberns Orchesterstück op. 6 Nr. 3. Ein Beitrag zur Theorie der Tonfelder von Albert Simon«, Jahrbuch 2008|2009 des Staatlichen Instituts für Musikforschung Preußischer Kulturbesitz, Mainz u. a.: Schott, 87-121.

Pousseur, Henry (1957), „Zur Methodik«, in: Die Reihe. Informationen über serielle Musik, Bd. 3: Musikalisches Handwerk, hg. von Herbert Eimert, Wien u.a.: Universal, 46-87. 